\title{
Data driven mathematical model of colon cancer progression
}

\author{
Arkadz Kirshtein ${ }^{1}$, Shaya Akbarinejad ${ }^{1, \dagger}$, Wenrui $\mathrm{Hao}^{2, \dagger}$ (D), \\ Trang Le ${ }^{1}$, Rachel A. Aronow ${ }^{1}$ and Leili Shahriyari ${ }^{1, \star}$ (1)
}

$\begin{array}{ll}1 & \text { Department of Mathematics and Statistics, University of Massachusetts Amherst, Amherst, MA, USA } \\ 2 & \text { Department of Mathematics, Pennsylvania State University, University Park, PA, USA } \\ \star & \text { Correspondence: lshahriyari@umass.edu } \\ \dagger & \text { These authors contributed equally to this work. }\end{array}$

\begin{abstract}
Every colon cancer has its own unique characteristics, and therefore may respond differently to identical treatments. Here, we develop a data driven mathematical model for the interaction network of key components of immune microenvironment in colon cancer. We estimate the relative abundance of each immune cell from gene expression profiles of tumors, and group patients based on their immune patterns. Then we compare the tumor sensitivity and progression in each of these groups of patients, and observe differences in the patterns of tumor growth between the groups. For instance, in tumors with a smaller density of naive macrophages than activated macrophages, a higher activation rate of macrophages leads to an increase in cancer cell density, demonstrating a negative effect of macrophages. Other tumors however, exhibit an opposite trend, showing a positive effect of macrophages in controlling tumor size. Although the results indicate that for all patients, the size of the tumor is sensitive to the parameters related to macrophages such as their activation and death rate, this research demonstrates that no single biomarker could predict the dynamics of tumors.
\end{abstract}

Keywords: colon cancer; data driven mathematical model; immune pattern; sensitivity analysis; gene expression profiles; tumor deconvolution; macrophages; T-cells; dendritic cells; HMGB1

\section{Introduction}

Recent studies show that many cancers arise from sites of chronic inflammation [1-4]. Balkwill et. al. [5] provide a list of inflammatory conditions that predispose an individual to cancer, in particular to colorectal cancer. Indeed, inflammatory bowel diseases like ulcerative colitis and colonic Crohn's disease are strongly associated with colorectal cancer [6]. In one experiment, chronic ulcerative colitis was induced in mice and, fourteen weeks later, the mice developed colitis-associated cancer (CAC) [7].

Most common cancer treatments are designed to kill tumor cells. However, the way in which cells die is very important, because dying cells may release molecules that initiate an immune response. We shall refer to cells that go through the process of necrotic cell death as necrotic cells. Necrotic cells are known to release damage-associated molecular pattern (DAMP) molecules such as high mobility group box 1 (HMGB1), which triggers immune responses $[8,9]$. In particular, HMGB1 activates dendritic cells [10]. There is an evidence that the expressions of HMGB1 and RAGE, its receptor, are significantly higher in ulcerative colitis than in control cases [11]. HMGB1 has been observed in other cancers, as a result of treatments by radiotherapy and chemotherapy $[10,12-14]$.

In colon cancer, activated $\mathrm{CD} 8^{+} \mathrm{T}$ cells enhance production of necrotic cells by expressing high levels of cytokines like IFN- $\gamma$ and FasL [15]. Necrotic cells and macrophages release HMGB1 to activate dendritic cells [10], which leads to activation of T-cells [16]. In addition, intestinal epithelial cells, which are in close contact with DCs, activate dendritic cells by releasing molecules like thymic stromal lymphopoietin (TSLP) $[17,18]$. Once activated, dendritic 
bioRxiv preprint doi: https://doi.org/10.1101/2020.11.02.365668; this version posted November 4, 2020. The copyright holder for this preprint (which was not certified by peer review) is the author/funder, who has granted bioRxiv a license to display the preprint in perpetuity. It is made available under aCC-BY-NC 4.0 International license.

cells release cytokines STAT4, STAT6, and IL-4,which induce differentiation of naive T-cells into effector T cells (Th1, Th17, and Th2) [19]. CD4 ${ }^{+}$T-cells can also become activated by TNF- $\alpha$, which is released by $M_{1}$ macrophages [20]. Activated CD4 ${ }^{+}$T-cells release IL-2, 4, 5, 13 and 17 to activate killer cells like $\mathrm{CD} 8^{+}$T-cells $[16,21,22]$. CD ${ }^{+}{ }^{+}$T-cells also release IFN- $\gamma$, which activates $M_{1}$ macrophages [23,24]. Activated macrophages and $\mathrm{CD}^{+}$effector T-cells release tumor-promoting cytokines interleukin 6 (IL-6) [25]. IL-6 promotes tumor growth by activating STAT3 in intestinal epithelial cells [26].

All these observations indicate the importance of the relative abundance of various immune cells, as well as their interaction networks, in the colonic tumors' initiation and progression. In the present paper, we develop a data driven mathematical model of colon cancer with emphasis on the role of immune cells. We use cancer patients' data to estimate the percentage of each immune cell types in their primary tumors. The developed mathematical model is based on the network shown in Figure 1, and it is represented by a system of ordinary differential equations (ODEs) within the tumor.

\section{Materials and Methods}

\subsection{Mathematical model}

We develop a mathematical model for colon cancer based on the interaction network among key players in colon cancer shown in Figure 1, and the list of variables is given in Table 1. The model is represented by a system of differential equations for concentrations and changing in time in unit of day. For clarity, we develop a simplified model in terms of ordinary differential equations. For biochemical processes $A+B \rightarrow C$, we use the mass action law $\frac{d C}{d t}=\lambda A B$, where $\lambda$ is production rate of $C[27,28]$. Throughout the paper, we use the symbol $\lambda$ for production, activation or proliferation rates, and the symbol $\delta$ for decay, natural death (apoptosis) or premature death (necrosis) rates.

Table 1: Model's Variables. Names and descriptions of variables used in the model.

\begin{tabular}{|c|l|l|}
\hline Variable & Name & Description \\
\hline \hline$T_{N}$ & Naive T-cells & \\
\hline$T_{h}$ & Helper T-cells & \\
\hline$T_{C}$ & Cytotoxic cells & \\
\hline$T_{r}$ & Regulatory T-cells & \\
\hline$D_{n}$ & Naive dendritic cells & \\
\hline$D$ & Activated dendritic cells & antigen presenting cells \\
\hline$M$ & Macrophages & \\
\hline$C$ & Cancer cells & \\
\hline$N$ & Nectrotic cells & \\
\hline$H$ & HMGB1 & includes effects of IL-6, IL-17, IL-21 and IL-22 \\
\hline$\mu_{1}$ & Carcinogenic cytokines \\
\hline$\mu_{2}$ & Immunosuppresive agents & includes effects of IL-10 and CCL20 \\
\hline$I_{\gamma}$ & IFN- $\gamma$ & \\
\hline$G_{\beta}$ & TGF- $\beta$ & \\
\hline
\end{tabular}

\subsubsection{Cytokine approximation}

In order to reduce the complexity of the system, we treat some of cytokines as independent variables and approximate the value of other cytokines through already existing variables. Additionally, we combine the cytokines that have a similar function in the interaction network (Figure 1). So, we combine IL-6, IL-17, IL-21 and IL-22 and denote their sum by the variable 
bioRxiv preprint doi: https://doi.org/10.1101/2020.11.02.365668; this version posted November 4, 2020. The copyright holder for this preprint (which was not certified by peer review) is the author/funder, who has granted bioRxiv a license to display the preprint in perpetuity. It is made available under aCC-BY-NC 4.0 International license.

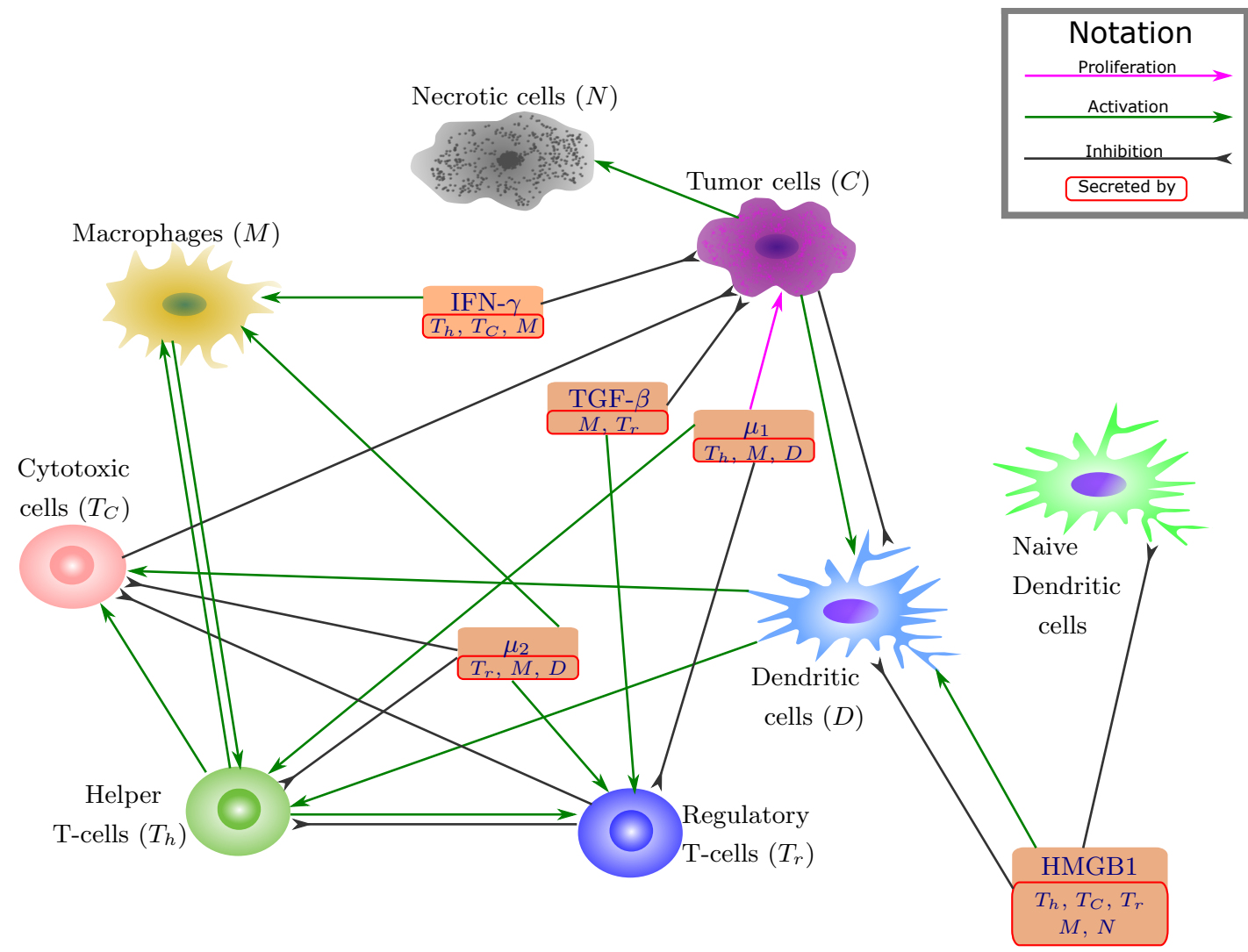

Figure 1: Network of cells and cytokines. Sharp arrows indicate activation or proliferation, and the blucked arrow indicates inhibitions.

$\mu_{1}$. We also combine IL-10 and CCL20 and denote their sum by the variable $\mu_{2}$. The cytokines treated as model variables are HMGB1, IFN- $\gamma$, TGF- $\beta$, IL- 6 , and IL- 10 . We then model the dynamics of cytokines in the following way.

HMGB1 is passively released from necrotic cells [29], or actively secreted from activated T-cells cells and macrophages [30,31]. Thus we can model the dynamics of HMGB1 by the equation:

$$
\frac{d[H]}{d t}=\lambda_{H N}[N]+\lambda_{H M}[M]+\lambda_{H T_{h}}\left[T_{h}\right]+\lambda_{H T_{C}}\left[T_{C}\right]+\lambda_{H T_{r}}\left[T_{r}\right]-\delta_{H}[H]
$$

IL-6 is secreted by TAMs [25,32-34], helper T-cells [25,34-36] and sub-population of dendritic cells $[37,38]$. IL-17, IL-21 and IL-22 are produced by helper T-cells [39]. So the resulting dynamics for $\left[\mu_{1}\right]$ can be written as

$$
\frac{d\left[\mu_{1}\right]}{d t}=\lambda_{\mu_{1} T_{h}}\left[T_{h}\right]+\lambda_{\mu_{1} M}[M]+\lambda_{\mu_{1} D}[D]-\delta_{\mu_{1}}\left[\mu_{1}\right] .
$$

IL-10 is produced by macrophages [40,41], dendritic cells [37,42] and T-reg cells [35,39,43,44]. CCL20 is produced by macrophages [45]. Thus, the equation for $\left[\mu_{2}\right]$ is

$$
\frac{d\left[\mu_{2}\right]}{d t}=\lambda_{\mu_{2} M}[M]+\lambda_{\mu_{2} D}[D]+\lambda_{\mu_{2} T_{r}}\left[T_{r}\right]-\delta_{\mu_{2}}\left[\mu_{2}\right] .
$$

IFN- $\gamma$ is secreted by a sub-population of macrophages [40,46-49], helper T-cells $[23,24]$ and cytotoxic cells [15], which results in the following equation:

$$
\frac{d\left[I_{\gamma}\right]}{d t}=\lambda_{I_{\gamma} T_{h}}\left[T_{h}\right]+\lambda_{I_{\gamma} T_{C}}\left[T_{C}\right]+\lambda_{I_{\gamma} M}[M]-\delta_{I_{\gamma}}\left[I_{\gamma}\right] .
$$


TGF- $\beta$ is produced by macrophages $[40,41]$ and T-reg cells $[35,39,43,50]$ leading to the equaiton:

$$
\frac{d\left[G_{\beta}\right]}{d t}=\lambda_{G_{\beta} M}[M]+\lambda_{G_{\beta} T_{r}}\left[T_{r}\right]-\delta_{G_{\beta}}\left[G_{\beta}\right] .
$$

Other cytokines, like IL-2, IL-4, IL-5, and IL-13, we consider to be in a quasi-equilibrium state, i.e. proportional to the concentration of cells that secrete/produce them. In particular, IL-2, IL-5, and IL-13 are produced by CD4+ T-cells $[16,22,51]$, so we consider

$$
\begin{aligned}
{[I L-2] } & \approx \text { Const } \times\left[T_{h}\right], \\
{[I L-5] } & \approx \text { Const } \times\left[T_{h}\right], \\
{[I L-13] } & \approx \text { Const } \times\left[T_{h}\right] .
\end{aligned}
$$

IL-4 is also produced both by CD4+ T-cells $[16,22,51]$ and dendritic cells [19], so we take

$$
[I L-4] \approx \text { Const } \times\left[T_{h}\right]+\text { Const } \times[D] .
$$

IL-12 secreted by macrophages [40,41] and dendritic cells $[32,33,37,39,52,53]$, thus can be approximated as

$$
[I L-12] \approx \text { Const }[M]+\text { Const }[D]
$$

while IL-23 and TNF- $\alpha$ are secreted solely by macrophages [32,33], hence their approximation is

$$
[I L-23] \approx \operatorname{Const}[M], \quad[T N F-\alpha] \approx \operatorname{Const}[M]
$$

\subsubsection{T-cells}

In this model we differentiate four subgroups of T-cells: naive, helper, cytotoxic, and regulatory.

Naive T-cells, $T_{N}$, are not necessarily part of tumor micro-environment, as they usually are activated within lymph nodes. However, making activation rates for other types of T-cells proportional to the density of naive cells creates a better controlled system and avoids unlimited exponential growth. Thus, we summarize the equation for the dynamics of the naive T-cells after detailing the equations of other types of T-cells.

Helper T-cells can be activated with antigen presentation by dendritic cells [16]. CD4+ T-cells can be additionally activated by IL-12, while Th17 are activated by IL-6, TNF- $\alpha$, and IL-23 [39]. Regulatory T-cells inhibit protective immune response (helper and cytotoxic T-cells) in several ways including production of immunosuppresive cytokines such as IL-10 and CCL20 as well as through contact-dependent mechanisms [39]. Additionally, we introduce the apoptosis rate for helper cells $\delta_{T_{h}}$. The resulting equation is

$$
\frac{d\left[T_{h}\right]}{d t}=\left(\lambda_{T_{h} D}[D]+\lambda_{T_{h} M}[M]+\lambda_{T_{h} \mu_{1}}\left[\mu_{1}\right]\right)\left[T_{N}\right]-\left(\delta_{T_{h} \mu_{2}}\left[\mu_{2}\right]+\delta_{T_{h} T_{r}}\left[T_{r}\right]+\delta_{T_{h}}\right)\left[T_{h}\right] .
$$

The variable corresponding to cytotoxic cells accounts for the effects of cytotoxic T-lymphocytes (mainly CD8+ T-cells) and possibly natural killer cells. CD8+ T-cells are activated by IL-2, IL-4, IL-5, and IL-13 [16,22, 51]. Cumulative effect of these cytokines can be written as

$$
[I L-2,4,5,13] \approx \text { Const } \times\left[T_{h}\right]+\text { Const } \times[D] .
$$

Activation of natural killer cells requires IL-2 [54], which is already included. We also include inhibitory effects mediated by T-reg cells. The dynamics of $T_{C}$ cell group is modeled by the following equation:

$$
\frac{d\left[T_{C}\right]}{d t}=\left(\lambda_{T_{C} T_{h}}\left[T_{h}\right]+\lambda_{T_{C} D}[D]\right)\left[T_{N}\right]-\left(\delta_{T_{C} \mu_{2}}\left[\mu_{2}\right]+\delta_{T_{C} T_{r}}\left[T_{r}\right]+\delta_{T_{C}}\right)\left[T_{C}\right] .
$$


Regulatory T-cells can be activated by IL-2 $[39,55,56]$, CCL20 [45] and TGF- $\beta[39,50]$. IL-6 suppresses T-reg differentiation and shifts it towards T-helper type [57]. The resulting dynamics can be described as follow:

$$
\frac{d\left[T_{r}\right]}{d t}=\left(\lambda_{T_{r} T_{h}}\left[T_{h}\right]+\lambda_{T_{r} \mu_{2}}\left[\mu_{2}\right]+\lambda_{T_{r} G_{\beta}}\left[G_{\beta}\right]\right)\left[T_{N}\right]-\left(\delta_{T_{r} \mu_{1}}\left[\mu_{1}\right]+\delta_{T_{r}}\right)\left[T_{r}\right] .
$$

Combining all activation and introducing independent naive T-cell production $A_{T_{N}}$, we get the following equation for naive T-cells:

$$
\begin{aligned}
\frac{d\left[T_{N}\right]}{d t}= & A_{T_{N}}-\left(\lambda_{T_{h} D}[D]+\lambda_{T_{h} M}[M]+\lambda_{T_{h} \mu_{1}}\left[\mu_{1}\right]\right)\left[T_{N}\right] \\
& -\left(\lambda_{T_{C} T_{h}}\left[T_{h}\right]+\lambda_{T_{C} D}[D]\right)\left[T_{N}\right] \\
& -\left(\lambda_{T_{r} T_{h}}\left[T_{h}\right]+\lambda_{T_{r} \mu_{2}}\left[\mu_{2}\right]+\lambda_{T_{r} G_{\beta}}\left[G_{\beta}\right]\right)\left[T_{N}\right] \\
& -\delta_{T_{N}}\left[T_{N}\right] .
\end{aligned}
$$

\subsubsection{Dendritic cells}

Dendritic cells become activated by HMGB1 [10] and TSLP, which is released by epithelial cells $[17,18]$. We take TSLP in quasi-equilibrium state as

$$
[T S L P] \approx \text { Const } \times[C]
$$

On the other hand multiple factors induced by cancer cells may promote apoptosis of dendritic cells [58-62]. Additionally, there's evidence that HMGB1 can reduce the maturation rate of dendritic cells [44,62]. Introducing the independent production rate of naive dendritic cells $A_{D_{N}}$, we get the following system for dynamics of naive $\left(D_{N}\right)$ and activated $(D)$ dendritic cells:

$$
\begin{aligned}
\frac{d\left[D_{N}\right]}{d t} & =A_{D_{N}}-\left(\lambda_{D H}[H]+\lambda_{D C}[C]\right)\left[D_{N}\right]-\left(\delta_{D H}[H]+\delta_{D}\right)\left[D_{N}\right], \\
\frac{d[D]}{d t} & =\left(\lambda_{D H}[H]+\lambda_{D C}[C]\right)\left[D_{N}\right]-\left(\delta_{D H}[H]+\delta_{D C}[C]+\delta_{D}\right)[D] .
\end{aligned}
$$

\subsubsection{Macrophages}

There are two main sub-types of macrophages: M1 and M2. M1 phenotype can be activated by IFN- $\gamma$, while M2 can be activated IL- 4 and IL-13, which are secreted by helper T-cells [40,41]. Additionally there's a possibility of tumor associated macrophage (TAM) activation by IL$10[40,63,64]$. Introducing naive $\left(M_{N}\right)$ and activated $(M)$ TAMs, as well as production rate for naive macrophages $A_{M}$, we can write the following system:

$$
\begin{aligned}
\frac{d\left[M_{N}\right]}{d t} & =A_{M}-\left(\lambda_{M \mu_{2}}\left[\mu_{2}\right]+\lambda_{M I_{\gamma}}\left[I_{\gamma}\right]+\lambda_{M T_{h}}\left[T_{h}\right]\right)\left[M_{N}\right]-\delta_{M}\left[M_{N}\right], \\
\frac{d[M]}{d t} & =\left(\lambda_{M \mu_{2}}\left[\mu_{2}\right]+\lambda_{M I_{\gamma}}\left[I_{\gamma}\right]+\lambda_{M T_{h}}\left[T_{h}\right]\right)\left[M_{N}\right]-\delta_{M}[M] .
\end{aligned}
$$

Next, to simplify the system we introduce the total amount of macrophages $M_{0}=\left[M_{N}\right]+[M]$. Adding the above equations we get $\frac{d M_{0}}{d t}=A_{M}-\delta_{M} M_{0}$. If we assume initial conditions for $M_{0}$ to be at the equilibrium $M_{0}=A_{M} / \delta_{M}$, then $M_{0}$ will remain constant at all times. Then we can express naive macrophages as $\left[M_{N}\right]=M_{0}-[M]$ and write the resulting equation for macrophages as follows:

$$
\frac{d[M]}{d t}=\left(\lambda_{M \mu_{2}}\left[\mu_{2}\right]+\lambda_{M I_{\gamma}}\left[I_{\gamma}\right]+\lambda_{M T_{h}}\left[T_{h}\right]\right)\left(M_{0}-[M]\right)-\delta_{M}[M] .
$$




\subsubsection{Cancer cells}

Cancer cells are epithelial cells with abnormally high growth and abnormally small death rate (apoptosis). Additional loss of apoptosis in cancer cells is induced by IL-6 [58, 60, 65, 66]. In addition to innate abnormally high proliferation rate $\lambda_{C}$, proliferation in cancer can be stimulated by expression of STAT3 in cancer cells, where STAT3 is activated by cytokines such as IL-6, IL-17, IL-21, and IL-22 [39,67]. On the other hand, cancer development is suppressed by TGF- $\beta[39,68-70]$, IL-12 and IFN- $\gamma[39]$; the suppressive properties of IL-12 are mediated by IFN- $\gamma$ [71] (so it is not directly included in the equation). Cytotoxic T-cells also directly target cancer cells for destruction [39]. In cancer modeling, proliferation is traditionally taken to be proportional to $[C]\left(1-[C] / C_{0}\right)$, where $C_{0}$ is the total capacity $[72,73]$. Thus the resulting equation is

$$
\frac{d[C]}{d t}=\left(\lambda_{C}+\lambda_{C \mu_{1}}\left[\mu_{1}\right]\right)[C]\left(1-\frac{[C]}{C_{0}}\right)-\left(\delta_{C G_{\beta}}\left[G_{\beta}\right]+\delta_{C I_{\gamma}}\left[I_{\gamma}\right]+\delta_{C T_{C}}\left[T_{C}\right]+\delta_{C}\right)[C]
$$

\subsubsection{Necrotic cells}

We designate cells which go through the process of necrotic cell death as necrotic cells. Since there is a limited amount of resources in the tumor microenvironment, and cells are under pressure, there are always some necrotic cells produced by the tumor. In addition, when activated cytotoxic T-cells kill colorectal cancer cells by expressing high levels of cytokines like IFN- $\gamma$ and FasL [15], a fraction of the cancer cells may go through the stage of first becoming necrotic cells. Therefore, the rate of "production" of the necrotic cells is given by the fraction of dying cancer cells, and the resulting dynamics can be written as follows:

$$
\frac{d[N]}{d t}=\alpha_{N C}\left(\delta_{C G_{\beta}}\left[G_{\beta}\right]+\delta_{C I_{\gamma}}\left[I_{\gamma}\right]+\delta_{C T_{C}}\left[T_{C}\right]+\delta_{C}\right)[C]-\delta_{N}[N]
$$

\subsection{Non-dimensionalization and sensitivity analysis}

For additional numerical stability and to eliminate scale dependence, we perform non-dimensionalization of the system. For variable $X$ converging to a steady state $X_{\infty}$, we consider non-dimensional variable $\bar{X}=X / X_{\infty}$. Then, $\bar{X}$ satisfies the equation

$$
\frac{d \bar{X}}{d t}=F(\bar{X}, \theta, t) .
$$

The (first order) solution sensitivity $S$ with respect to the model parameter $\theta=\left\{\theta_{i}\right\}_{i=\overline{1, N}}$ is defined as a vector

$$
S_{i}=\frac{d \bar{X}}{d \theta_{i}}, i=\overline{1, N} .
$$

In general, the sensitivity vector is time dependent and varies for different solutions and parameter sets [74-76]. However, here we consider sensitivity at the steady state of the equation. The sensitivity of each parameter in the neighborhood of a chosen parameter set $\Omega(\theta)$ is defined as

$$
\mathcal{S}_{i}=\int_{\Omega} S_{i}(\theta) d \theta,
$$

where the integration is evaluated numerically with sparse grid points $[77,78]$.

We choose three quantities of interest for the sensitivity analysis: amount of cancer cells $C$, total amount of cells, and a measure of how fast the system is converging to the steady state. Consider general steady state system as follows

$$
F\left(X^{\star}, \theta\right)=0
$$


where $X^{\star}$ is the equilibrium. We then consider a small perturbation to $X^{\star}$ as $\bar{X}(t)=X^{\star}+\varepsilon X_{1}(t)$. The linearized system becomes

$$
\frac{d X_{1}(t)}{d t}=\nabla F\left(X^{\star}, \theta\right) X_{1}(t)+O(\varepsilon),
$$

where $\nabla F(X, \theta)$ is the Jacobian matrix of $F(X, \theta)$ with respect to $X$. Thus we have $X_{1}(t) \approx$ $e^{\nabla F\left(X^{\star}, \theta\right) t}$ and the minimal eigenvalue $\min \lambda\left(\nabla F\left(X^{\star}, \theta\right)\right)$ determines how fast it reaches the steady state.

\subsection{Cancer patients' data}

In recent years, several tumor deconvolution methods have been developed to estimate the relative abundance of various cell types in a tumor from its gene expression profile. A review of these methods [79] and an application of CIBERSORTx on renal cancer [80] show a great performance of CIBERSORTx model. To identify the immune profiles of colonic tumors, we applied CIBERSORTx [81] on RNA-seq gene expression profiles of primary tumors of patients with colon cancer from the TCGA project of COAD downloaded from UCSC Xena web portal. There are a total of 329 patients with RSEM normalized RNA-seq data in $\log _{2}$ scale. Before applying CIBERSORTx on this dataset, we transformed the gene expression values to the linear space.

\subsection{Numerical methods}

In order to solve the time dependent system, we employ the SciPy odeint function [82] using initial conditions based on patients with the smallest tumor area within each cluster. The sensitivity analysis of the system based on the cancer and total cell density at steady state is obtained analytically by differentiating the steady state equation with respect to the parameters, namely,

$$
\nabla F\left(X^{\star}, \theta\right) \frac{d X^{*}}{d \theta}+\frac{\partial F\left(X^{\star}, \theta\right)}{\partial \theta}=0 .
$$

Then to obtain the sensitivity, $\frac{d X^{*}}{d \theta}$, one just needs to numerically invert the matrix $\nabla F$. On the other hand, it is hard to analytically obtain the sensitivity of the eigenvalue, so instead a finite-difference approach is used as follows:

$$
\frac{d \min \lambda\left(\nabla F\left(X^{\star}, \theta\right)\right)}{d \theta} \approx \frac{\min \lambda\left(\nabla F\left(X^{\star}, \theta+\frac{1}{2} \Delta \theta\right)\right)-\min \lambda\left(\nabla F\left(X^{\star}, \theta-\frac{1}{2} \Delta \theta\right)\right)}{\Delta \theta},
$$

where $\Delta \theta$ is a small discretization parameter.

\section{Results}

We derived an ODE system describing complex dynamics in the colon cancer microenvironment. Assuming non-negative values of all parameters and non-negative initial conditions, the solution of the system remains non-negative and globally bounded (see Appendix A).

\subsection{Patient data analysis}

We downloaded TCGA clinical data, which includes tumor dimension, stage, age at diagnosis, and gene expression profiles of primary tumors for patients with colon cancer from GDC portal. We applied CIBERSORTx B-mode on gene expression profiles to estimate the fraction of each immune cell type in each tumor. Elbow method applied on estimated cell fractions (Figure 2-A) showed the existence of five distinct immune patterns. We hence performed K-means clustering with $K=5$, to group patients based on the immune pattern of their primary tumors. Figure 2-B 
bioRxiv preprint doi: https://doi.org/10.1101/2020.11.02.365668; this version posted November 4, 2020. The copyright holder for this preprint (which was not certified by peer review) is the author/funder, who has granted bioRxiv a license to display the preprint in perpetuity. It is made available under aCC-BY-NC 4.0 International license.

shows average cell fractions for patients divided into five clusters based on their immune profiles. To investigate the effect of these immune patterns on the dynamics of tumors, we model each cluster separately, and based on the steady state assumptions (see Appendix B), we generate a parameter set for each cluster, with steady state values derived from patient data as described further.

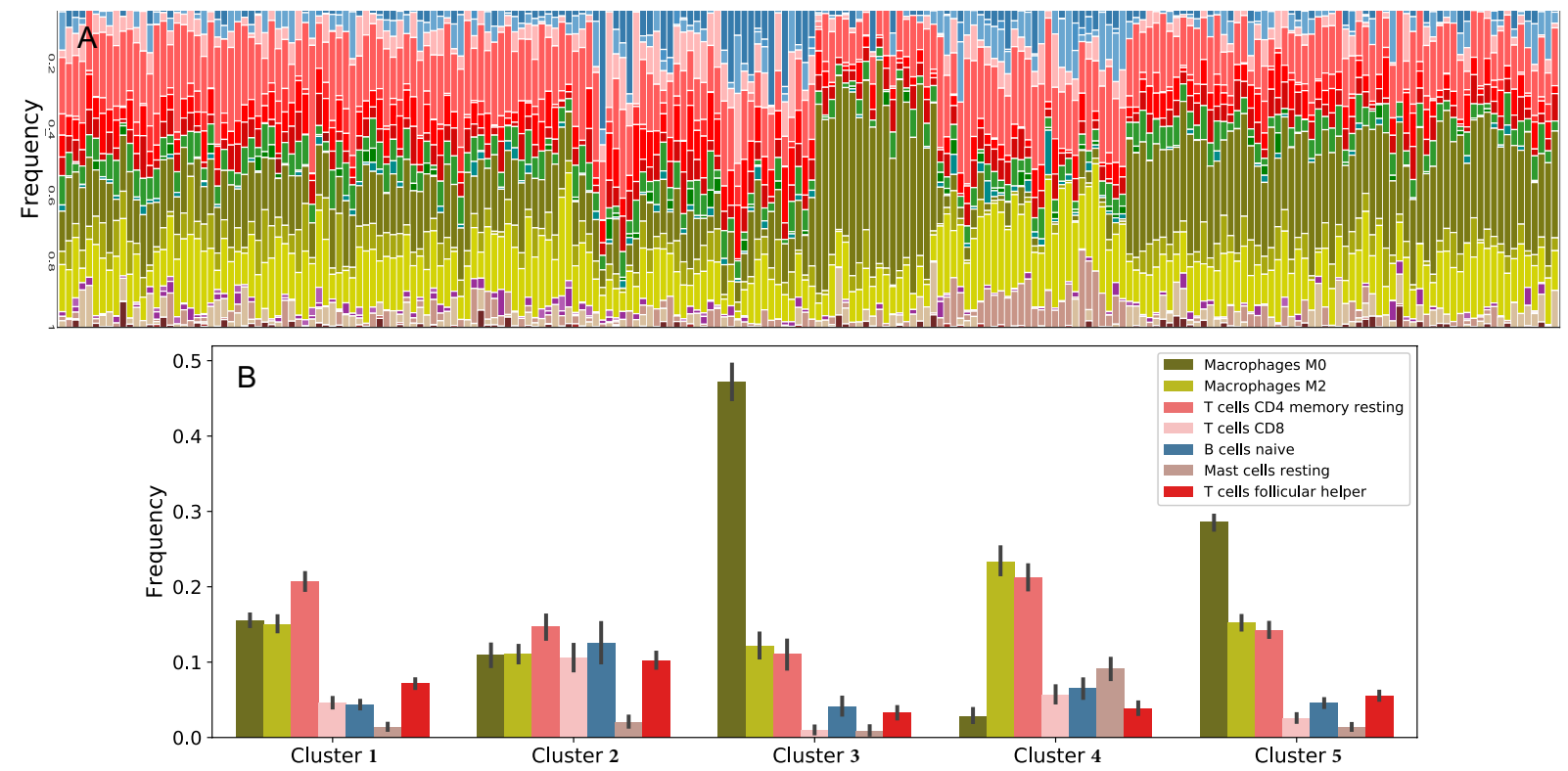

Figure 2: Immune cell fractions. Sub-figure A shows the fraction of immune cells in each colonic tumor. Sub-figure B indicates the frequencies of immune cell types in each cluster of patients. Clusters were formed based on variations of 22 immune cell types, some of which were later combined and others were not included in the model. Cell frequencies on this figure are average within the cluster and vertical bars show the standard deviations

The deconvolution data, described in section 2.3, only provides the ratios of immune cells in the tumor microenvironment. For each patient $P$, we define their size of tumor $(\operatorname{size}(P))$ to be the product of the longest and the shortest dimensions of the tumor, and we assume total cell density is proportional to the size of the tumor:

$$
\text { Total_Cell_Density }_{P}=\alpha_{\operatorname{dim}} \frac{\operatorname{size}(P)}{\frac{1}{K} \sum_{\text {all } P} \operatorname{size}(P)} .
$$

Then, we take each immune cell value from deconvolution multiplied by $0.4 \alpha_{\text {dim }} \sum$ (Immune cell ratios) and

$$
C=\frac{2}{3} \text { (Total_Cell_Density }- \text { Total_Immune_Density) }, \quad N=0.5 C \text {. }
$$

For each cluster, we consider the mean of variables of patients with tumor size above the average of their cluster as the steady state values of the variables for the corresponding cluster. The resulting data is given in Table 2 .

While macrophage capacity $M_{0}$ is derived from the data, we assume cancer capacity to be $C_{0}=2 * C$ for both mean-based and extreme-based data. We choose $\alpha_{\operatorname{dim}}=1.125 \mathrm{e}+05$ to approximately match the average density of cancer cells across all patients to $4.5 \mathrm{e}+04 \mathrm{cells} / \mathrm{cm}^{3}$ reported in [83]. However, it is important to note that this is no more than scaling and has no effect on the dynamics of the dimensionless system. 
bioRxiv preprint doi: https://doi org/10.1101/2020.11.02.365668; this version posted November 4, 2020. The copyright holder for this preprint (which was not certified by peer review) is the author/funder, who has granted bioRxiv a license to display the preprint in perpetuity. It is made available under aCC-BY-NC 4.0 International license.

Table 2: Steady state cell densities. Mean cell densities in cells $/ \mathrm{cm}^{3}$ for each cluster are used to derive parameter sets for sensitivity analysis and dynamics computations. Calculated based only on patients with tumor size above average for each cluster.

\begin{tabular}{lcccccccc}
\hline Cluster & $\mathbf{T}_{\mathbf{N}}^{\infty}$ & $\mathbf{T}_{\mathbf{h}}^{\infty}$ & $\mathbf{T}_{\mathbf{C}}^{\infty}$ & $\mathbf{T}_{\mathbf{r}}^{\infty}$ & $\mathbf{D}_{\mathbf{N}}^{\infty}$ & $\mathbf{D}^{\infty}$ & $\mathbf{M}^{\infty}$ & $\mathbf{M}_{\mathbf{0}}$ \\
\hline 1 & $1.4914 \mathrm{e}+4$ & $4.6358 \mathrm{e}+3$ & $2.5845 \mathrm{e}+3$ & $2.3891 \mathrm{e}+3$ & $3.0504 \mathrm{e}+2$ & $6.0214 \mathrm{e}+2$ & $1.1798 \mathrm{e}+4$ & $2.1004 \mathrm{e}+4$ \\
2 & $1.1429 \mathrm{e}+4$ & $6.0411 \mathrm{e}+3$ & $5.3853 \mathrm{e}+3$ & $3.3646 \mathrm{e}+3$ & $1.0329 \mathrm{e}+2$ & $5.1299 \mathrm{e}+2$ & $8.6227 \mathrm{e}+3$ & $1.6445 \mathrm{e}+4$ \\
3 & $9.2381 \mathrm{e}+3$ & $1.3864 \mathrm{e}+3$ & $1.1139 \mathrm{e}+3$ & $2.7910 \mathrm{e}+3$ & $1.8878 \mathrm{e}-1$ & $1.8635 \mathrm{e}+2$ & $6.7972 \mathrm{e}+3$ & $3.2146 \mathrm{e}+4$ \\
4 & $1.3878 \mathrm{e}+4$ & $2.4910 \mathrm{e}+3$ & $3.2172 \mathrm{e}+3$ & $2.2783 \mathrm{e}+3$ & $1.4196 \mathrm{e}+2$ & $6.2154 \mathrm{e}+2$ & $1.2931 \mathrm{e}+4$ & $1.5761 \mathrm{e}+4$ \\
5 & $1.0262 \mathrm{e}+4$ & $3.7844 \mathrm{e}+3$ & $1.6853 \mathrm{e}+3$ & $2.6394 \mathrm{e}+3$ & $8.0199 \mathrm{e}+1$ & $1.9084 \mathrm{e}+2$ & $1.1603 \mathrm{e}+4$ & $2.8198 \mathrm{e}+4$ \\
\hline & $\mathbf{C}^{\infty}$ & $\mathbf{N}^{\infty}$ & $\mu_{1}^{\infty}$ & $\mu_{2}^{\infty}$ & $\mathbf{H}^{\infty}$ & $\mathbf{I}_{\gamma}^{\infty}$ & $\mathbf{G}_{\beta}^{\infty}$ & \\
\hline 1 & $9.1531 \mathrm{e}+4$ & $4.5765 \mathrm{e}+4$ & $1.6328 \mathrm{e}+2$ & $1.2987 \mathrm{e}+3$ & $8.9811 \mathrm{e}+3$ & 8.5737 & $1.9037 \mathrm{e}+4$ & \\
2 & $9.7064 \mathrm{e}+4$ & $4.8532 \mathrm{e}+4$ & $1.7552 \mathrm{e}+2$ & $1.3249 \mathrm{e}+3$ & $8.5279 \mathrm{e}+3$ & 10.5677 & $2.2275 \mathrm{e}+4$ & \\
3 & $9.0029 \mathrm{e}+4$ & $4.5014 \mathrm{e}+4$ & $1.9866 \mathrm{e}+2$ & $1.2906 \mathrm{e}+3$ & $9.5122 \mathrm{e}+3$ & 0.8287 & $2.5145 \mathrm{e}+4$ & \\
4 & $9.6956 \mathrm{e}+4$ & $4.8478 \mathrm{e}+4$ & $1.1410 \mathrm{e}+2$ & $3.3689 \mathrm{e}+2$ & $5.1782 \mathrm{e}+3$ & 1.2703 & $8.1734 \mathrm{e}+3$ & \\
5 & $8.0584 \mathrm{e}+4$ & $4.0292 \mathrm{e}+4$ & $1.2058 \mathrm{e}+2$ & $7.1551 \mathrm{e}+2$ & $7.7848 \mathrm{e}+3$ & 5.7892 & $2.6260 \mathrm{e}+4$ & \\
\hline
\end{tabular}

For the time-dependent calculations, we choose initial conditions for each cluster based on patients with the smallest tumor size. The relative values are given in Table 3. The dynamics with initial conditions based on other patients is presented in Appendix C.

Table 3: Dimensionless initial conditions. Values of initial conditions for the dimensionless system derived from the patients with the smallest tumor size.

\begin{tabular}{cccccccc}
\hline Cluster & $\mathbf{T}_{\mathbf{N}} / \mathbf{T}_{\mathbf{N}}^{\infty}$ & $\mathbf{T}_{\mathbf{h}} / \mathbf{T}_{\mathbf{h}}^{\infty}$ & $\mathbf{T}_{\mathbf{C}} / \mathbf{T}_{\mathbf{C}}^{\infty}$ & $\mathbf{T}_{\mathbf{r}} / \mathbf{T}_{\mathbf{r}}^{\infty}$ & $\mathbf{D}_{\mathbf{N}} / \mathbf{D}_{\mathbf{N}}^{\infty}$ & $\mathbf{D} / \mathbf{D}^{\infty}$ & $\mathbf{M} / \mathbf{M}^{\infty}$ \\
\hline 1 & 0.9311 & 1.2492 & 2.4626 & 0.6872 & 1.6328 & 0.0003 & 0.6737 \\
2 & 1.2302 & 1.3155 & 1.5210 & 0.5107 & 2.0461 & 2.7822 & 1.2920 \\
3 & 1.1997 & 0.8555 & $1.6948 \mathrm{e}-4$ & 0.6572 & 1.0000 & $1.0130 \mathrm{e}-3$ & 1.4150 \\
4 & 1.4471 & 0.1571 & 0.5823 & 0.8910 & 5.6827 & 4.2945 & 0.9259 \\
5 & 0.6794 & 2.6119 & 1.6294 & 1.8819 & $2.3538 \mathrm{e}-3$ & 0.4542 & 0.7749 \\
\hline & $\mathbf{C} / \mathbf{C}^{\infty}$ & $\mathbf{N} / \mathbf{N}^{\infty}$ & $\mu_{1} / \mu_{1}^{\infty}$ & $\mu_{2} / \mu_{2}^{\infty}$ & $\mathbf{H} / \mathbf{H}^{\infty}$ & $\mathbf{I}_{\gamma} / \mathbf{I}_{\gamma}^{\infty}$ & $\mathbf{G}_{\beta} / \mathbf{G}_{\beta}^{\infty}$ \\
\hline 1 & $3.1466 \mathrm{e}-4$ & 0.0 & 0.4971 & 0.5124 & 1.4712 & 3.8892 & 0.2549 \\
2 & $2.9672 \mathrm{e}-4$ & 0.0 & 0.7578 & 0.1790 & 0.6036 & 0.9385 & 0.5566 \\
3 & $3.1991 \mathrm{e}-4$ & 0.0 & 0.1335 & 0.8419 & 1.2566 & 0.0 & 0.6851 \\
4 & $2.9706 \mathrm{e}-4$ & 0.0 & 0.4137 & 5.7720 & 1.4630 & 0.0 & 2.5629 \\
5 & $3.5741 \mathrm{e}-4$ & 0.0 & 0.4587 & 2.2979 & 1.1835 & 0.4084 & 0.3457 \\
\hline
\end{tabular}

\subsection{Sensitivity analysis}

We perform sensitivity analysis of the non-dimensionalized system with parameters derived from patient data through steady state assumptions. Table 2 contains the steady state values used for each cluster, and Appendix B shows the parameter derivation and non-dimensionalization in detail. We use cancer cells, total cell density and minimal eigenvalue of the Jacobian of the ODE system as the variables of interest in the sensitivity analysis. Minimal eigenvalue of the Jacobian serves as a measure of how fast the system converges to the steady state. Figure 3-A shows the four most sensitive parameters for each cluster. Additionally, to evaluate the effect of immune microenvironment on cancer, we look at the sensitivity of cancer cells and total cell density excluding the parameters appearing in the equations for cancer and necrotic cells. The resulting data denoted as "Immune sensitivity" is given in Figure 3-B. 


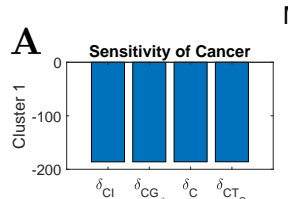

Most sensitive parameters
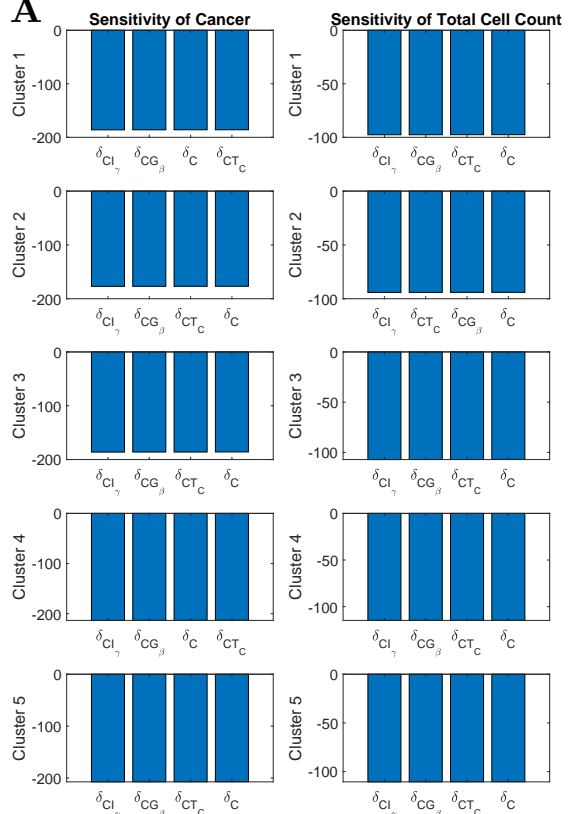
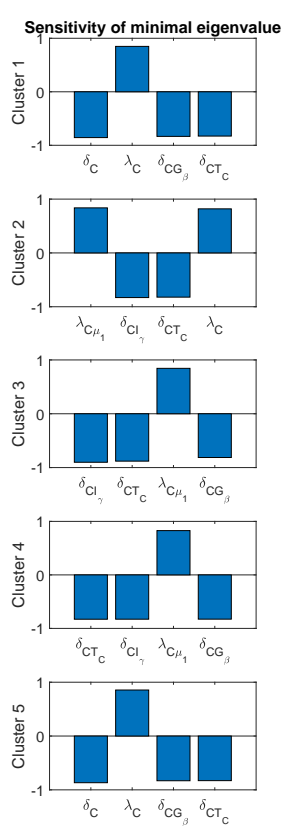

Most sensitive immune parameters
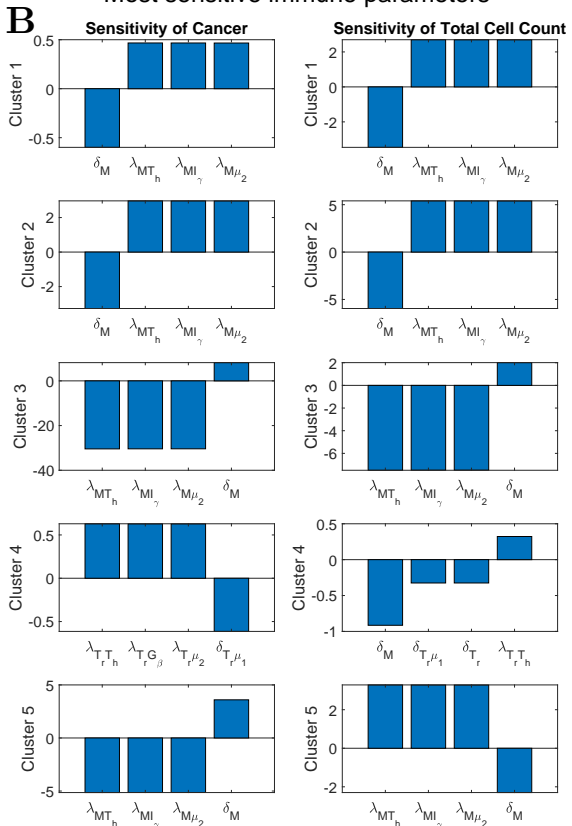

Figure 3: Sensitivity analysis. The first, second, and third columns of sub-figure A respectively present the results of non-dimensional sensitivity of cancer cell density, total cell density and minimal eigenvalue of the Jacobian of the system at the steady state. Minimal eigenvalue is used as a measure of how fast the system converges to the steady state. Sub-figure B shows the sensitive parameters related to immune cells. Each row of plots shows the most sensitive parameters for each cluster of patients.

Across all clusters the most sensitive parameters are cancer proliferation and death rates directly present in the cancer equation (13). From third column in Figure 3-A, we conclude that for all clusters increased cancer proliferation coefficients correspond to faster convergence to the steady state, while increased cancer death rates lead to a slower convergence. When considering immune sensitivity presented on figure 3 -B, in clusters $1,2,3$, and 5 , the most sensitive immune parameters are those corresponding to the activation and decay rates of macrophages, with only sensitivity levels being different between clusters and variables. In clusters 1 and 2 , which include tumors with a smaller density of naive macrophages than activated macrophages, an increase in decay rate of macrophages causes a decrease in the density of cancer cells and total cell density. On the other hand, an increase in any of the activation rates for macrophages causes an increase in both quantities of interest. However, for clusters 3 and 5 , which include tumors with a higher density of naive macrophages than activated macrophages, the effects are reversed. Interestingly, for cluster 3, the increase in macrophage activation rate results in both lower cancer cell density and total cell density, with latter sensitivity being noticeably smaller by absolute value. On the other hand, for cluster 5 the increase in macrophage activation rate results in lower cancer cell density, but higher total cell density. This can be explained by a significant increase in immune cell density, which for cluster 5 is even higher than the corresponding decrease in cancer cell density. All these results demonstrate that at the steady state tumor-associated macrophages could have different effects on different clusters of patients depending on their immune profile.

The outlying cluster 4 , which consists of tumors with a significantly small density of naive macrophages compared to the other clusters, is less sensitive to the activation rates of macrophages. The most sensitive immune parameters for cancer cell density are those related to the activation and degradation of regulatory T-cells. The results indicate that increased regulatory response activation rate corresponds to an increase in the cancer cell density, while an increase in T-reg cell degradation rate results in a decrease in cancer cell density, demonstrating that for this clus- 
ter of patients regulatory T-cells have mostly negative effect. Importantly, the most sensitive parameter for the total cell density is still the decay rate of macrophages, and macrophages still have a negative effect; i.e. the faster decay of macrophases leads to the smaller tumors in the steady state.

\subsection{Dynamic of tumor microenvironment}

We investigate the dynamics of each variable, with parameters derived for each cluster based on steady state assumptions (see Table 2 for steady state values and Tables A1-A3 for parameter values) and initial conditions of patients with the smallest tumor (see Table 3). Figures 4 and 5 are respectively show the dynamics of cell densities and cytokines expressions.
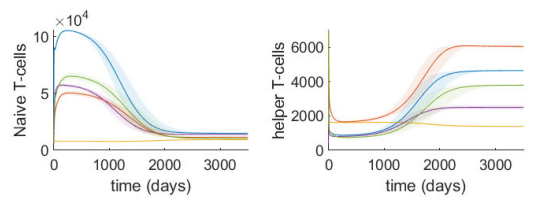

Cell dynamics
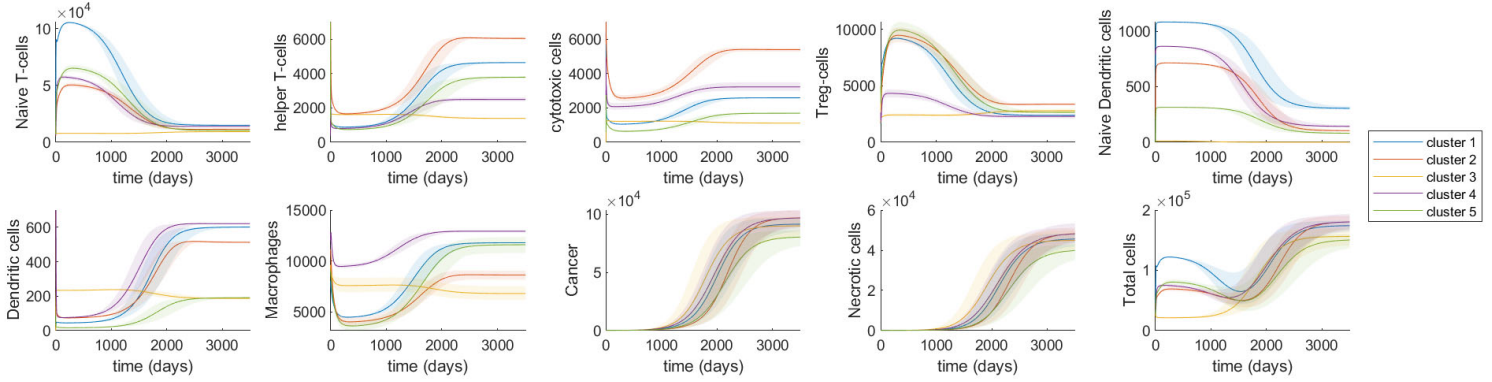

Figure 4: Cells' dynamics in colonic tumors. Time evolution of cells' density $\left(\mathrm{cell} / \mathrm{cm}^{3}\right)$ for each cell type in the model and total cell density. Different colors represent the models derived for different clusters of patients and shaded regions represent the $10 \%$ variation in the most sensitive parameters.
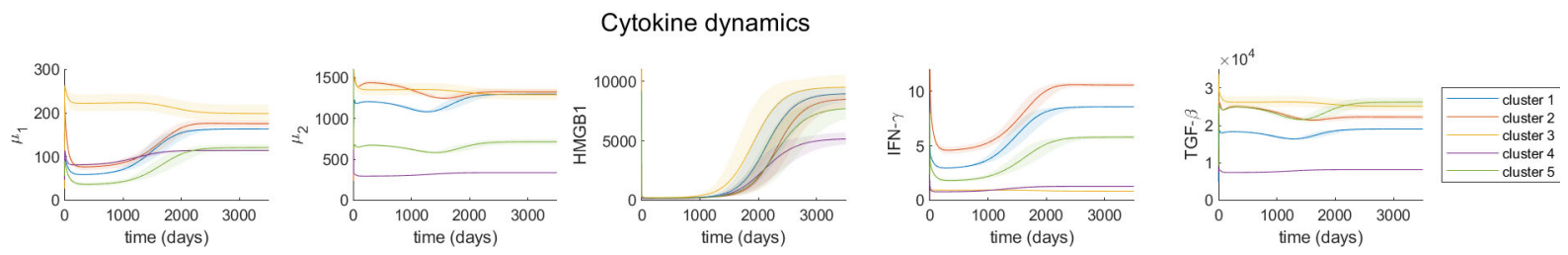

Figure 5: Cytokines' dynamics in colonic tumors. Time evolution of RNA-seq expression rate of cytokines. Different colors represent the models derived from different clusters of patients and shaded regions represent the $10 \%$ variation in the most sensitive parameters.

For most clusters, cancer cells grow as helper T-cells, cytotoxic cells (cytotoxic T-cells and NK cells), dendritic cells and macrophages increase in density over time, while naive T-cells, regulatory T-cells and naive dendritic cells decrease in density. The increase in cytotoxic cells along with tumor progression is somewhat contradicting to the finding in $[84,85]$ that colon primary tumor growth is associated with decreased cytotoxic T-cells density. However, there is no correlation between tumor size and cytotoxic cells in the TCGA data of colonic primary tumors. Moreover, it is important to note that in our model cancer cells' growth is multiple times faster than the rate of change of any immune cells (Figure 4). Thus, even though cytotoxic cells density grows over time, the tumor is growing at a much faster rate. Since tumor cells activate dendritic cells which then activate cytotoxic cells, it is reasonable to see some growth of cytotoxic cells when tumor cells density increases rapidly.

Cluster 2 and 4 have the highest cancer cell density at steady state and also the highest growth rate of cancer cells. Cluster 2's cancer cells start out with lowest growth rate, but at around 1,800 days grow significantly faster and end up growing the fastest among all clusters. Cluster 2 has the highest density of helper T-cells and cytotoxic cells, both in the early stages 
of cancer development and at steady state, as well as the highest growth rate of these cells. However, cluster 2 has rather low density and low growth rate of macrophages.

Cluster 4, having the largest density of activated macrophages and a significantly small density of naive macrophages (Figure 2-B), first demonstrates average cancer growth rate, but then increases and has one of the 2 highest cancer cell densities at the steady state (Figure 4). Similar to cluster 2, cluster 4 has high density of cytotoxic cells (CD8 T-cells and NK cells) initially and at steady state. Both cluster 2 and 4 have low growth rate of macrophages and high density of dendritic cells, compared to other clusters. Immune cell dynamics of cluster 2 and 4 demonstrate that high density of cytotoxic cells and dendritic cells, along with low growth rate of macrophages correlate with high growth rate of cancer cells.

However, unlike cluster 2, cluster 4 has low growth rate of cytotoxic cells and helper T-cells, and low density of helper T-cells overall. Though both cluster 2 and 4 have low growth rate of macrophages, cluster 4 has the highest density of macrophages among all clusters, while cluster 2 has the second lowest macrophages density. Regulatory T-cells also behave very differently between cluster 2 and cluster 4 . Cluster 2 has high density and high decline rate of regulatory T-cells over time, but cluster 4 has both low density and low decline rate of this cell. These observations suggest that cell densities alone cannot predict cancer progression and there are no specific biomarkers that are sufficient to model tumor growth. Instead, a time series immune interaction network with tumor cells can be useful in modeling cancer development.

Cluster 5, with the density of activated macrophages being slightly less than naive macrophages (Figure 2-B), has the lowest cancer cell density at steady state and the lowest cancer cell growth of all clusters (Figure 4). This cluster has the lowest growth rate and density at initial condition and steady state of naive dendritic cells, activated dendritic cells and cytotoxic cells, except for cytotoxic cells density at steady state (second lowest). It also has the highest growth rate of macrophages among the five clusters. This observation might imply that slow tumor growth is associated with low density and growth rate of naive and activated dendritic cells, cytotoxic cells and high growth rate of macrophages.

Cluster 1, which is characterized by the second largest population of macrophages and helper T-cells, demonstrates that dendritic cells alone cannot be chosen as a marker of cancer progression, as it has the second highest dendritic cell population, but only third highest cancer population at the steady state, being surpassed by cluster 2 .

Cluster 3, being a clear outlier in the immune dynamics, has near zero density of naive dendritic cells. This alone prevents it from creating significant variations in the immune response during the cancer progression. It is interesting to note, that while almost unchecked by immune responses, this cluster initially demonstrates noticeably highest cancer growth rate, but results in the second lowest cancer density at the steady state.

Tumor cytokines' dynamics (Figure 5) indicate that as tumor grows, HMGB1, IFN- $\gamma$ and $\mu_{1}$ (IL-6, IL-17, IL-21, IL-22) increase in density, but TGF- $\beta$ and $\mu_{2}$ (IL-10, CCL20) stay relatively constant. Cluster 2 and 4, which have the highest cancer cell growth rate among all clusters, show different cytokines' behaviors throughout time. At steady state, cluster 4 has significantly lower densities of all cytokines in our model than cluster 2, despite the fact that they have the same cancer cell density then. Cluster 4 also has much lower growth rate of $\mu_{1}$, HMGB1 and IFN- $\gamma$ compared to cluster 2 . Cluster 1 and 5 have more similar growth rate of these cytokines as cluster 2 , even though they have rather different tumor growth rate from cluster 2 . Thus, the density or growth of any specific cytokine is not an adequate predictor of tumor progression, and we need the full interaction network to effectively model the cancer cell growth.

Additionally within each cluster we look at the dynamics of cancer and total cell density with different initial conditions, each derived from a different patient in that cluster. See Appendix $\mathrm{C}$, and specifically figures A1-A5, for more details on different initial conditions and resulting dynamics. This result indicates that even within the same cluster different initial immune profile may cause dramatic difference in cancer progression rate. Additionally, while the dynamics of cancer cell density remains monotone across all patients, we observe oscillatory behavior in the 
total cell density. This can be explained by a temporary surge of immune cell density at the early stages of cancer, which also appears to correlate with slower cancer progression rate. The only cluster which does not exhibit this oscillatory behavior is cluster 3. As mentioned before, due to lack of naive dendritic cells cluster 3 does not show significant immune cell density variations, which are the source of oscillatory behavior for other clusters.

\section{Discussion}

There are many mathematical models for cancer [86-106]. The approach of many of these mathematical models is varying the parameters values and initial conditions to investigate their effects on the dynamics. However, new advances in tumor deconvolution techniques help us to utilize cancer patients' data in order to develop a data driven mathematical model of tumor growth. Using tumor deconvolution methods, we estimate the relative abundance of various cell types from gene expression profiles of tumors. The machine learning algorithm of K-means clustering indicates the existence of five distinct groups of colon cancers based on their immune patterns. The comparison of tumor behaviours in these groups suggests that the dynamics of tumors strongly depends on their immune structure.

While it would be ideal to use time course gene expression data of colon cancer patients in our framework, the availability of these time series data sets is limited. In order to combat this limitation, clustering was used to group patients with similar immune patterns and treat each group as time course data based on the size of tumor, which means the data points with small tumor density are considered data from early stages and the data points with large tumor density are considered data from late stages. This method of artificially creating time course data is based on the assumption that immune variation between clusters of patients at any time point is greater than the immune variation within one cluster during tumor progression.

The mathematical model with these assumptions indicate that high density of cytotoxic Tcells and dendritic cells and low growth rate of macrophages are associated with high growth rate of cancer cells, while low density and growth rate of naive and active dendritic cells, cytotoxic T-cells and high growth rate of macrophages correlate with slow tumor growth. In particular, our results imply that macrophages' growth rate is negatively correlated with tumor growth rate, which is consistent with the observation that high level of macrophages is associated with favorable outcome of colon cancer patients in [84]. This study [84] also shows that high level of regulatory T-cells is related to poor prognosis of patients, which supports our results that regulatory T-cells decrease in density as cancer cells increase in density. Another similar finding between [84] and our study is that the density of dendritic cells increases along with tumor progression.

There is a significant body of research analyzing statistical and mathematical relations of particular components of tumor microenvironment and the disease progression and outcome for subsequent establishment of prognostic biomarkers [83,107-115]. Our result demonstrates that the dynamics of cancer development cannot be captured by one specific biomarker, but can rather be characterized by complex time-dependent interactions between many components of the immune system and tumor tissue. It is important to further develop and analyze these tumor-immune cell interactions and how they affect different possibilities of treatment.

One way forward is the design of patient-specific models [116-119]. These models can utilize the tumor immune microenvironment deconvolution and clustering methods for available patient data as detailed in this paper. New prognosis can be built based on established dynamics from patients with similar immune characteristics. To better match the dynamics of the model to real patient data, various parameter fitting algorithms can be utilized [120-123]. Another possible improvement is a transition to a partial differential equations model [124] to analyze spatial properties of tumor development as well as temporal.

Author Contributions: conceptualization, L.S.; methodology, A.K., L.S., W.H., S.A.; software, A.K.; validation, A.K.; formal analysis, A.K., T.L., R.A.; investigation, A.K.; resources, S.A., T.L., R.A.; data curation, 
bioRxiv preprint doi: https://doi.org/10.1101/2020.11.02.365668; this version posted November 4, 2020. The copyright holder for this preprint (which was not certified by peer review) is the author/funder, who has granted bioRxiv a license to display the preprint in perpetuity. It is made available under aCC-BY-NC 4.0 International license.

S.A., T.L., R.A.; writing-original draft preparation, A.K., L.S., S.A., W.H., T.L., R.A.; visualization, A.K., S.A., W.H.; supervision, L.S.; project administration, L.S.; funding acquisition, L.S.

Funding: This research was funded by National Cancer Institute of the National Institutes of Health under Award Number R21CA242933.

Conflicts of Interest: The authors declare no conflict of interest. The funders had no role in the design of the study; in the collection, analyses, or interpretation of data; in the writing of the manuscript, or in the decision to publish the results.

Data and Code Availability: Publicly available TCGA clinical data was downloaded from GDC portal. Figure 2 was obtained using TumorDecon software: https://github.com/ShahriyariLab/TumorDecon. Python scripts for computations and MatLab scripts for plotting the results presented on figures 3-5 and A1-A5 are available here: https://github.com/ShahriyariLab/Data-driven-mathematical-model-for-colon-cancer.

\section{Abbreviations}

The following abbreviations are used in this manuscript:

$\begin{array}{ll}\text { CAC } & \text { colitis-associated cancer } \\ \text { CCL20 } & \begin{array}{l}\text { chemokine (C-C motif) ligand } 20 \\ \text { COAD }\end{array} \\ \text { colon adenocarcinoma } \\ \text { DAMP } & \text { damage-associated molecular pattern } \\ \text { DCs } & \text { dendritic cells } \\ \text { FasL } & \text { fas ligand } \\ \text { GEP } & \text { gene expression profiles } \\ \text { HMGB1 } & \text { high mobility group box 1 } \\ \text { IFN } & \text { interferon } \\ \text { IL } & \text { interleukin } \\ \text { NF- } \kappa \text { B } & \text { nuclear factor kappa B } \\ \text { NK cells } & \text { natural killer cells } \\ \text { ODE } & \text { ordinary differential equation } \\ \text { RAGE } & \text { receptor for advanced glycation endproducts } \\ \text { RNA-seq } & \text { ribonucleic acid sequencing } \\ \text { STAT } & \text { signal transducer and activator of transcription } \\ \text { TAM } & \text { tumor associated macrophage } \\ \text { TCGA } & \text { the cancer genome atlas } \\ \text { TGF } & \text { transforming growth factor } \\ \text { TNF } & \text { tumor necrosis factor } \\ \text { TSLP } & \text { thymic stromal lymphopoietin }\end{array}$

\section{References}

[1] L. M. Coussens and Z. Werb, "Inflammation and cancer," Nature, vol. 420, no. 6917, pp. 860-867, 2002.

[2] Q. Li, S. Withoff, and I. M. Verma, "Inflammation-associated cancer: NF- $\kappa$ B is the lynchpin," jun 2005.

[3] S. Maeda and M. Omata, "Inflammation and cancer: Role of nuclear factor-kappaB activation," Cancer Science, vol. 99, no. 5, pp. 836-842, 2008.

[4] E. N. Arwert, E. Hoste, and F. M. Watt, "Epithelial stem cells, wound healing and cancer," Nature Reviews Cancer, vol. 12, no. 3, pp. 170-180, 2012.

[5] F. Balkwill, K. a. Charles, and A. Mantovani, "Smoldering and polarized inflammation in the initiation and promotion of malignant disease," Cancer Cell, vol. 7, no. 3, pp. 211-217, 2005 .

[6] J. M. Rhodes and B. J. Campbell, "Inflammation and colorectal cancer: IBD-associated and sporadic cancer compared," Trends in Molecular Medicine, vol. 8, no. 1, pp. 10-16, 2002 .

[7] H. Z. Imtiyaz, E. P. Williams, M. M. Hickey, S. a. Patel, A. C. Durham, L.-j. Yuan, R. Hammond, P. a. Gimotty, B. Keith, and M. C. Simon, "Hypoxia-inducible factor 2alpha regulates macrophage function in mouse models of acute and tumor inflammation.," The Journal of clinical investigation, vol. 120, pp. 2699-714, aug 2010. 
[8] P. Scaffidi, T. Misteli, and M. E. Bianchi, "Release of chromatin protein HMGB1 by necrotic cells triggers inflammation.," Nature, vol. 418, pp. 191-195, jul 2002.

[9] M. T. Lotze and K. J. Tracey, "High-mobility group box 1 protein (HMGB1): nuclear weapon in the immune arsenal.," Nature reviews. Immunology, vol. 5, no. 4, pp. 331-342, 2005.

[10] L. Apetoh, F. Ghiringhelli, A. Tesniere, A. Criollo, C. Ortiz, R. Lidereau, C. Mariette, N. Chaput, J.-P. P. Mira, S. Delaloge, F. André, T. Tursz, G. Kroemer, and L. Zitvogel, "The interaction between HMGB1 and TLR4 dictates the outcome of anticancer chemotherapy and radiotherapy," Immunological Reviews, vol. 220, pp. 47-59, dec 2007.

[11] Z. Hu, X. Wang, L. Gong, G. Wu, X. Peng, and X. Tang, "Role of high-mobility group box 1 protein in inflammatory bowel disease," Inflammation Research, vol. 64, no. 8, pp. 557-563, 2015.

[12] E. B. Golden, D. Frances, I. Pellicciotta, S. Demaria, M. Helen Barcellos-Hoff, and S. C. Formenti, "Radiation fosters dose-dependent and chemotherapy-induced immunogenic cell death," OncoImmunology, vol. 3, no. 4, p. e28518, 2014.

[13] P. Schildkopf, B. Frey, F. Mantel, O. J. Ott, E. M. Weiss, R. Sieber, C. Janko, R. Sauer, R. Fietkau, and U. S. Gaipl, "Application of hyperthermia in addition to ionizing irradiation fosters necrotic cell death and HMGB1 release of colorectal tumor cells," Biochemical and Biophysical Research Communications, vol. 391, no. 1, pp. 1014-1020, 2010.

[14] L. Liu, M. Yang, R. Kang, Z. Wang, Y. Zhao, Y. Yu, M. Xie, X. Yin, K. M. Livesey, M. T. Lotze, D. Tang, and L. Cao, "HMGB1-induced autophagy promotes chemotherapy resistance in leukemia cells.," Leukemia : official journal of the Leukemia Society of America, Leukemia Research Fund, U.K, vol. 25, no. 1, pp. 23-31, 2011.

[15] X. Xu, X. Y. Fu, J. Plate, and A. S. Chong, "IFN-gamma induces cell growth inhibition by Fas-mediated apoptosis: requirement of STAT1 protein for up-regulation of Fas and FasL expression.," Cancer research, vol. 58, pp. 2832-7, jul 1998.

[16] G. Kroemer, L. Galluzzi, O. Kepp, and L. Zitvogel, "Immunogenic Cell Death in Cancer Therapy," Annual Review of Immunology, vol. 31, pp. 51-72, mar 2013.

[17] Y.-J. Liu, "TSLP," in Epithelial Cell and Dendritic Cell Cross Talk, vol. 18, ch. 1, pp. 1-25, 2009 .

[18] L. W. Peterson and D. Artis, "Intestinal epithelial cells: regulators of barrier function and immune homeostasis.," Nature reviews. Immunology, vol. 14, pp. 141-53, mar 2014.

[19] D. C. Baumgart and S. R. Carding, "Inflammatory bowel disease: cause and immunobiology.," Lancet (London, England), vol. 369, pp. 1627-40, may 2007.

[20] B. K. Popivanova, K. Kitamura, Y. Wu, T. Kondo, T. Kagaya, S. Kaneko, M. Oshima, C. Fujii, and N. Mukaida, "Blocking TNF-alpha in mice reduces colorectal carcinogenesis associated with chronic colitis.," The Journal of clinical investigation, vol. 118, pp. 560-70, feb 2008.

[21] R. J. Xavier and D. K. Podolsky, "Unravelling the pathogenesis of inflammatory bowel disease.," Nature, vol. 448, pp. 427-434, jul 2007.

[22] O. Boyman and J. Sprent, "The role of interleukin-2 during homeostasis and activation of the immune system," Nature Reviews Immunology, vol. 12, pp. 180-190, mar 2012. 
[23] C. F. Nathan, H. W. Murray, M. E. Wiebe, and B. Y. Rubin, "Identification of interferongamma as the lymphokine that activates human macrophage oxidative metabolism and antimicrobial activity.," The Journal of experimental medicine, vol. 158, pp. 670-89, sep 1983.

[24] C. Bogdan, S. Stenger, M. Röllinghoff, and W. Solbach, "Cytokine interactions in experimental cutaneous leishmaniasis. Interleukin 4 synergizes with interferon- $\gamma$ to activate murine macrophages for killing ofLeishmania major amastigotes," European Journal of Immunology, vol. 21, pp. 327-333, feb 1991.

[25] M. J. Waldner and M. F. Neurath, "Colitis-associated cancer: the role of T cells in tumor development.," Seminars in immunopathology, vol. 31, pp. 249-56, jul 2009.

[26] S. Grivennikov, E. Karin, J. Terzic, D. Mucida, G.-Y. Yu, S. Vallabhapurapu, J. Scheller, S. Rose-John, H. Cheroutre, L. Eckmann, and M. Karin, "IL-6 and Stat3 are required for survival of intestinal epithelial cells and development of colitis-associated cancer.," Cancer cell, vol. 15, pp. 103-13, feb 2009.

[27] E. O. Voit, H. A. Martens, and S. W. Omholt, "150 years of the mass action law," PLoS Comput Biol, vol. 11, no. 1, p. e1004012, 2015.

[28] Y. Wang, C. Liu, P. Liu, and B. Eisenberg, "Field theory of reaction-diffusion: Mass action with an energetic variational approach," arXiv preprint arXiv:2001.10149, 2020.

[29] D. Süren, M. Yıldırım, Ö. Demirpençe, V. Kaya, A. S. Alikanoğlu, N. Bülbüller, M. Yıldız, and C. Sezer, "The role of high mobility group box 1 (HMGB1) in colorectal cancer.," Medical science monitor : international medical journal of experimental and clinical research, vol. 20, pp. 530-7, mar 2014.

[30] Z. S. Guo, Z. Liu, D. L. Bartlett, D. Tang, and M. T. Lotze, "Life after death: targeting high mobility group box 1 in emergent cancer therapies.," American journal of cancer research, vol. 3, no. 1, pp. 1-20, 2013.

[31] H. Wang, O. Bloom, M. Zhang, J. M. Vishnubhakat, M. Ombrellino, J. Che, A. Frazier, H. Yang, S. Ivanova, L. Borovikova, K. R. Manogue, E. Faist, E. Abraham, J. Andersson, U. Andersson, P. E. Molina, N. N. Abumrad, A. Sama, and K. J. Tracey, "HMG-1 as a late mediator of endotoxin lethality in mice.," Science (New York, N.Y.), vol. 285, pp. 248-51, jul 1999 .

[32] B. Beutler, D. Greenwald, J. D. Hulmes, M. Chang, Y.-C. E. Pan, J. Mathison, R. Ulevitch, and A. Cerami, "Identity of tumour necrosis factor and the macrophage-secreted factor cachectin," Nature, vol. 316, pp. 552-554, aug 1985.

[33] S. I. Grivennikov, F. R. Greten, and M. Karin, "Immunity, Inflammation, and Cancer," Cell, vol. 140, pp. 883-899, mar 2010.

[34] J. Mudter and M. F. Neurath, "IL-6 signaling in inflammatory bowel disease: Pathophysiological role and clinical relevance," Inflammatory Bowel Diseases, vol. 13, no. 8, pp. 1016-1023, 2007.

[35] J. Terzić, S. Grivennikov, E. Karin, and M. Karin, "Inflammation and Colon Cancer," Gastroenterology, vol. 138, no. 6, pp. 2101-2114, 2010.

[36] M. J. Waldner, S. Foersch, and M. F. Neurath, "Interleukin-6-a key regulator of colorectal cancer development.," International journal of biological sciences, vol. 8, no. 9, pp. 1248 $53,2012$. 
[37] A. L. Hart, H. O. Al-Hassi, R. J. Rigby, S. J. Bell, A. V. Emmanuel, S. C. Knight, M. a. Kamm, and A. J. Stagg, "Characteristics of intestinal dendritic cells in inflammatory bowel diseases," Gastroenterology, vol. 129, no. 1, pp. 50-65, 2005.

[38] C. Pasare and R. Medzhitov, "Toll pathway-dependent blockade of CD4+CD25+ T cellmediated suppression by dendritic cells.," Science (New York, N.Y.), vol. 299, pp. 1033-6, feb 2003.

[39] K. Wang and A. T. Vella, "Regulatory T Cells and Cancer: A Two-Sided Story," Immunological Investigations, vol. 45, pp. 797-812, nov 2016.

[40] S. Aras and M. R. Zaidi, "TAMeless traitors: macrophages in cancer progression and metastasis," British Journal of Cancer, vol. 117, pp. 1583-1591, nov 2017.

[41] X. Fan, H. Zhang, Y. Cheng, X. Jiang, J. Zhu, and T. Jin, "Double roles of macrophages in human neuroimmune diseases and their animal models," Mediators of inflammation, vol. 2016, 2016.

[42] A. Iwasaki and B. L. Kelsall, "Freshly isolated Peyer's patch, but not spleen, dendritic cells produce interleukin 10 and induce the differentiation of T helper type 2 cells," The Journal of experimental medicine, vol. 190, no. 2, pp. 229-240, 1999.

[43] J. K. H. Leman, S. K. Sandford, J. L. Rhodes, and R. A. Kemp, "Multiparametric analysis of colorectal cancer immune responses," World Journal of Gastroenterology, vol. 24, pp. 2995-3005, jul 2018.

[44] K. J. Cheng, M. A. Alshawsh, E. H. Mejia Mohamed, S. Thavagnanam, A. Sinniah, and Z. A. Ibrahim, "HMGB1: an overview of its versatile roles in the pathogenesis of colorectal cancer," Cellular Oncology, vol. 43, pp. 177-193, apr 2020.

[45] G. Deng, "Tumor-infiltrating regulatory T cells: origins and features.," American journal of clinical and experimental immunology, vol. 7, no. 5, pp. 81-87, 2018.

[46] S.-M. Ong, Y.-C. Tan, O. Beretta, D. Jiang, W.-H. Yeap, J. J. Y. Tai, W.-C. Wong, H. Yang, H. Schwarz, K.-H. Lim, P.-K. Koh, K.-L. Ling, and S.-C. Wong, "Macrophages in human colorectal cancer are pro-inflammatory and prime $\mathrm{T}$ cells towards an anti-tumour type-1 inflammatory response," European Journal of Immunology, vol. 42, pp. 89-100, jan 2012.

[47] L. Darwich, G. Coma, R. Peña, R. Bellido, E. J. J. Blanco, J. A. Este, F. E. Borras, B. Clotet, L. Ruiz, A. Rosell, and Others, "Secretion of interferon- $\gamma$ by human macrophages demonstrated at the single-cell level after costimulation with interleukin (IL)-12 plus IL-18," Immunology, vol. 126, no. 3, pp. 386-393, 2009.

[48] C. M. Robinson, D. O'Dee, T. Hamilton, and G. J. Nau, "Cytokines involved in interferongamma production by human macrophages.," Journal of innate immunity, vol. 2, no. 1, pp. 56-65, 2010.

[49] M. R. Zaidi, S. Davis, F. P. Noonan, C. Graff-Cherry, T. S. Hawley, R. L. Walker, L. Feigenbaum, E. Fuchs, L. Lyakh, H. A. Young, T. J. Hornyak, H. Arnheiter, G. Trinchieri, P. S. Meltzer, E. C. De Fabo, and G. Merlino, "Interferon- $\gamma$ links ultraviolet radiation to melanomagenesis in mice.," Nature, vol. 469, pp. 548-53, jan 2011.

[50] Y. Liu, P. Zhang, J. Li, A. B. Kulkarni, S. Perruche, and W. Chen, "A critical function for TGF-beta signaling in the development of natural CD4+CD25+Foxp3+ regulatory $\mathrm{T}$ cells.," Nature immunology, vol. 9, pp. 632-40, jun 2008. 
[51] N. R. West, S. McCuaig, F. Franchini, and F. Powrie, "Emerging cytokine networks in colorectal cancer," Nature Reviews Immunology, vol. 15, pp. 615-629, sep 2015.

[52] S. E. Macatonia, N. A. Hosken, M. Litton, P. Vieira, C.-S. Hsieh, J. A. Culpepper, M. Wysocka, G. Trinchieri, K. M. Murphy, and A. O'Garra, "Dendritic cells produce IL-12 and direct the development of Th1 cells from naive CD4+ T cells.," The Journal of Immunology, vol. 154, no. 10, pp. 5071-5079, 1995.

[53] A. Legitimo, R. Consolini, A. Failli, G. Orsini, and R. Spisni, "Dendritic cell defects in the colorectal cancer," Human Vaccines and Immunotherapeutics, vol. 10, no. 11, pp. 3224$3235,2014$.

[54] A. Coppola, R. Arriga, D. Lauro, M. I. del Principe, F. Buccisano, L. Maurillo, P. Palomba, A. Venditti, and G. Sconocchia, "NK Cell Inflammation in the Clinical Outcome of Colorectal Carcinoma," Frontiers in Medicine, vol. 2, pp. 1-6, may 2015.

[55] J. D. Fontenot, J. P. Rasmussen, M. A. Gavin, and A. Y. Rudensky, "A function for interleukin 2 in Foxp3-expressing regulatory T cells," Nature immunology, vol. 6, no. 11, pp. 1142-1151, 2005.

[56] K. B. Vang, J. Yang, S. A. Mahmud, M. A. Burchill, A. L. Vegoe, and M. A. Farrar, "IL$2,-7$, and -15 , but not thymic stromal lymphopoeitin, redundantly govern CD4+Foxp3+ regulatory T cell development.," Journal of immunology (Baltimore, Md. : 1950), vol. 181, pp. 3285-90, sep 2008 .

[57] C. a. Hunter and S. a. Jones, "IL-6 as a keystone cytokine in health and disease," Nature Immunology, vol. 16, pp. 448-457, may 2015.

[58] S. E. Erdman and T. Poutahidis, "Roles for Inflammation and Regulatory T Cells in Colon Cancer," Toxicologic Pathology, vol. 38, pp. 76-87, jan 2010.

[59] Y. Ma, G. V. Shurin, Z. Peiyuan, and M. R. Shurin, "Dendritic cells in the cancer microenvironment," Journal of Cancer, vol. 4, no. 1, pp. 36-44, 2013.

[60] C. Menetrier-Caux, G. Montmain, M. C. Dieu, C. Bain, M. C. Favrot, C. Caux, and J. Y. Blay, "Inhibition of the differentiation of dendritic cells from CD34+ progenitors by tumor cells: role of interleukin-6 and macrophage colony-stimulating factor," Blood, The Journal of the American Society of Hematology, vol. 92, no. 12, pp. 4778-4791, 1998.

[61] C. Esche, A. Lokshin, G. V. Shurin, B. R. Gastman, H. Rabinowich, S. C. Watkins, M. T. Lotze, and M. R. Shurin, "Tumor's other immune targets: dendritic cells," Journal of leukocyte biology, vol. 66, no. 2, pp. 336-344, 1999.

[62] A. Kusume, T. Sasahira, Y. Luo, M. Isobe, N. Nakagawa, N. Tatsumoto, K. Fujii, H. Ohmori, and H. Kuniyasu, "Suppression of dendritic cells by HMGB1 is associated with lymph node metastasis of human colon cancer," Pathobiology, vol. 76, no. 4, pp. 155162,2009 .

[63] A. Sica, A. Saccani, and A. Mantovani, "Tumor-associated macrophages: a molecular perspective.," International immunopharmacology, vol. 2, pp. 1045-54, jul 2002.

[64] Y. Sakai, M. Honda, H. Fujinaga, I. Tatsumi, E. Mizukoshi, Y. Nakamoto, and S. Kaneko, "Common transcriptional signature of tumor-infiltrating mononuclear inflammatory cells and peripheral blood mononuclear cells in hepatocellular carcinoma patients.," Cancer research, vol. 68, pp. 10267-79, dec 2008. 
[65] A. Badache and N. E. Hynes, "Interleukin 6 inhibits proliferation and, in cooperation with an epidermal growth factor receptor autocrine loop, increases migration of T47D breast cancer cells," Cancer research, vol. 61, no. 1, pp. 383-391, 2001.

[66] M.-T. Lin, C.-Y. Juan, K.-J. Chang, W.-J. Chen, and M.-L. Kuo, "IL-6 inhibits apoptosis and retains oxidative DNA lesions in human gastric cancer AGS cells through up-regulation of anti-apoptotic gene mcl-1," Carcinogenesis, vol. 22, no. 12, pp. 1947-1953, 2001.

[67] H. Yu, M. Kortylewski, and D. Pardoll, "Crosstalk between cancer and immune cells: role of STAT3 in the tumour microenvironment.," Nature reviews. Immunology, vol. 7, pp. 41-51, jan 2007.

[68] H. L. Moses, E. Y. Yang, and J. A. Pietenpol, "TGF-beta stimulation and inhibition of cell proliferation: new mechanistic insights.," Cell, vol. 63, pp. 245-7, oct 1990.

[69] S. D. Markowitz and A. B. Roberts, "Tumor suppressor activity of the TGF-beta pathway in human cancers.," Cytokine $\&$ growth factor reviews, vol. 7, pp. 93-102, jun 1996.

[70] C. Y. Wang, J. R. Eshleman, J. K. Willson, and S. Markowitz, "Both transforming growth factor-beta and substrate release are inducers of apoptosis in a human colon adenoma cell line.," Cancer research, vol. 55, pp. 5101-5, nov 1995.

[71] M. A. Engel and M. F. Neurath, "Anticancer properties of the IL-12 family-focus on colorectal cancer," Current medicinal chemistry, vol. 17, no. 29, pp. 3303-3308, 2010.

[72] J. Folkman and M. Hochberg, "Self-regulation of growth in three dimensions," The Journal of experimental medicine, vol. 138, no. 4, pp. 745-753, 1973.

[73] H. Enderling, E. Sunassee, and J. J. Caudell, "Predicting patient-specific radiotherapy responses in head and neck cancer to personalize radiation dose fractionation," bioRxiv, p. $630806,2019$.

[74] G. Karagiannis, W. Hao, and G. Lin, "Calibrations and validations of biological models with an application on the renal fibrosis," International Journal for Numerical Methods in Biomedical Engineering, vol. 36, no. 5, p. e3329, 2020.

[75] S. Seefeld and W. R. Stockwell, "First-order sensitivity analysis of models with timedependent parameters: an application to pan and ozone," Atmospheric Environment, vol. 33, no. 18, pp. 2941-2953, 1999.

[76] I. H. Yang, "Uncertainty and sensitivity analysis of time-dependent effects in concrete structures," Engineering structures, vol. 29, no. 7, pp. 1366-1374, 2007.

[77] F. Heiss and V. Winschel, "Likelihood approximation by numerical integration on sparse grids," journal of Econometrics, vol. 144, no. 1, pp. 62-80, 2008.

[78] T. Gerstner and M. Griebel, "Numerical integration using sparse grids," Numerical algorithms, vol. 18, no. 3-4, p. 209, 1998.

[79] T. Le, R. Aronow, K. A, and S. L, "A review of digital cytometry methods: estimating the relative abundance of cell types in a bulk of cells," Briefing in Bioinformatics, p. accepted, 2020 .

[80] S. Su, S. Akbarinejad, and L. Shahriyari, "Immune classification of clear cell renal cell carcinoma," bioRxiv, 2020. 
[81] A. Newman, C. Steen, C. Liu, A. Gentles, A. Chaudhuri, F. Scherer, M. Khodadoust, M. Esfahani, B. Luca, D. Steiner, and M. Diehn, "Determining cell type abundance and expression from bulk tissues with digital cytometry.," Nature biotechnology, vol. 37, no. 7, pp. $773-782,2019$.

[82] P. Virtanen, R. Gommers, T. E. Oliphant, M. Haberland, T. Reddy, D. Cournapeau, E. Burovski, P. Peterson, W. Weckesser, J. Bright, S. J. van der Walt, M. Brett, J. Wilson, K. J. Millman, N. Mayorov, A. R. J. Nelson, E. Jones, R. Kern, E. Larson, C. J. Carey, İ. Polat, Y. Feng, E. W. Moore, J. VanderPlas, D. Laxalde, J. Perktold, R. Cimrman, I. Henriksen, E. A. Quintero, C. R. Harris, A. M. Archibald, A. H. Ribeiro, F. Pedregosa, P. van Mulbregt, and SciPy 1.0 Contributors, "SciPy 1.0: Fundamental Algorithms for Scientific Computing in Python," Nature Methods, vol. 17, pp. 261-272, 2020.

[83] K.-L. Liao, X.-F. Bai, and A. Friedman, "Mathematical Modeling of Interleukin-35 Promoting Tumor Growth and Angiogenesis," PLoS ONE, vol. 9, p. e110126, oct 2014.

[84] G. Bindea, B. Mlecnik, M. Tosolini, A. Kirilovsky, M. Waldner, A. C. Obenauf, H. Angell, T. Fredriksen, L. Lafontaine, A. Berger, et al., "Spatiotemporal dynamics of intratumoral immune cells reveal the immune landscape in human cancer," Immunity, vol. 39, no. 4, pp. 782-795, 2013.

[85] B. Mlecnik, M. Tosolini, A. Kirilovsky, A. Berger, G. Bindea, T. Meatchi, P. Bruneval, Z. Trajanoski, W.-H. Fridman, F. Pages, et al., "Histopathologic-based prognostic factors of colorectal cancers are associated with the state of the local immune reaction," Journal of clinical oncology, vol. 29, no. 6, pp. 610-618, 2011.

[86] L. E. Mehl, "A mathematical computer simulation model for the development of colonic polyps and colon cancer," Journal of surgical oncology, vol. 47, no. 4, pp. 243-252, 1991.

[87] D. Kirschner and J. C. Panetta, "Modeling immunotherapy of the tumor-immune interaction," Journal of mathematical biology, vol. 37, no. 3, pp. 235-252, 1998.

[88] N. Bellomo and L. Preziosi, "Modelling and mathematical problems related to tumor evolution and its interaction with the immune system," Mathematical and Computer Modelling, vol. 32 , pp. 413-452, aug 2000.

[89] E. G. Luebeck and S. H. Moolgavkar, "Multistage carcinogenesis and the incidence of colorectal cancer," Proceedings of the National Academy of Sciences, vol. 99, no. 23, pp. 15095-15100, 2002.

[90] N. Bellomo, A. Bellouquid, and E. De Angelis, "The modelling of the immune competition by generalized kinetic (Boltzmann) models: Review and research perspectives," Mathematical and Computer Modelling, vol. 37, no. 1-2, pp. 65-86, 2003.

[91] F. Michor, Y. Iwasa, H. Rajagopalan, C. Lengauer, and M. A. Nowak, "Linear model of colon cancer initiation," Cell cycle, vol. 3, no. 3, pp. 356-360, 2004.

[92] L. G. de Pillis, A. E. Radunskaya, and C. L. Wiseman, "A Validated Mathematical Model of Cell-Mediated Immune Response to Tumor Growth," Cancer Research, vol. 65, pp. 7950-7958, sep 2005.

[93] M. Robertson-Tessi, A. El-Kareh, and A. Goriely, "A mathematical model of tumor-immune interactions," Journal of Theoretical Biology, vol. 294, pp. 56-73, feb 2012.

[94] L. Shahriyari and N. L. Komarova, "Symmetric vs. asymmetric stem cell divisions: an adaptation against cancer?," PLoS ONE., vol. 8, p. e76195, oct 2013. 
[95] W.-C. Lo, E. W. Martin Jr, C. L. Hitchcock, and A. Friedman, "Mathematical model of colitis-associated colon cancer," Journal of theoretical biology, vol. 317, pp. 20-29, 2013.

[96] M. Sturrock, W. Hao, J. Schwartzbaum, and G. A. Rempala, "A mathematical model of pre-diagnostic glioma growth," Journal of theoretical biology, vol. 380, pp. 299-308, 2015.

[97] L. Shahriyari and N. L. Komarova, "The role of the bi-compartmental stem cell niche in delaying cancer," Physical Biology, vol. 12, p. 055001, jul 2015.

[98] L. Shahriyari, N. L. Komarova, and A. Jilkine, "The role of cell location and spatial gradients in the evolutionary dynamics of colon and intestinal crypts," Biology Direct, vol. 11, p. 42, dec 2016 .

[99] L. Shahriyari, "Cell dynamics in tumour environment after treatments," Journal of The Royal Society Interface, vol. 14, p. 20160977, feb 2017.

[100] L. Shahriyari and A. Mahdipour-Shirayeh, "Modeling dynamics of mutants in heterogeneous stem cell niche," Physical Biology, vol. 14, no. 1, 2017.

[101] M. K. Jolly, M. Boareto, B. G. Debeb, N. Aceto, M. C. Farach-Carson, W. A. Woodward, and H. Levine, "Inflammatory breast cancer: a model for investigating cluster-based dissemination," NPJ Breast Cancer, vol. 3, no. 1, pp. 1-8, 2017.

[102] A. Mahdipour-Shirayeh and L. Shahriyari, "Modeling Cell Dynamics in Colon and Intestinal Crypts: The Significance of Central Stem Cells in Tumorigenesis," Bulletin of Mathematical Biology, vol. 80, pp. 2273-2305, sep 2018.

[103] M. Renardy, A. Jilkine, L. Shahriyari, and C.-S. Chou, "Control of cell fraction and population recovery during tissue regeneration in stem cell lineages," Journal of Theoretical Biology, vol. 445, 2018.

[104] N. de Souza, "A model for tumor-immune interaction," Nature methods, vol. 15, no. 10, pp. $762-762,2018$.

[105] G. E. Mahlbacher, K. C. Reihmer, and H. B. Frieboes, "Mathematical modeling of tumorimmune cell interactions," Journal of Theoretical Biology, vol. 469, pp. 47-60, 2019.

[106] W. Sung, C. Grassberger, A. L. McNamara, L. Basler, S. Ehrbar, S. Tanadini-Lang, T. S. Hong, and H. Paganetti, "A tumor-immune interaction model for hepatocellular carcinoma based on measured lymphocyte counts in patients undergoing radiotherapy," Radiotherapy and Oncology, vol. 151, pp. 73-81, 2020.

[107] W. Hao and A. Friedman, "Serum uPAR as biomarker in breast cancer recurrence: A mathematical model," PLoS ONE, vol. 11, no. 4, pp. 1-24, 2016.

[108] H. Y. Wang and R.-F. Wang, "Regulatory T cells and cancer," Current Opinion in Immunology, vol. 19, pp. 217-223, apr 2007.

[109] D. Japink, M. P. G. Leers, M. N. Sosef, and M. Nap, "CEA in activated macrophages. New diagnostic possibilities for tumor markers in early colorectal cancer.," Anticancer research, vol. 29, pp. 3245-51, aug 2009.

[110] W. Yue, Y. Lin, X. Yang, B. Li, J. Liu, and R. He, "Thymic stromal lymphopoietin (TSLP) inhibits human colon tumor growth by promoting apoptosis of tumor cells," Oncotarget, vol. 7, no. 13, pp. 16840-16854, 2016. 
[111] C. Evans, I. Morrison, A. Heriot, J. Bartlett, C. Finlayson, A. Dalgleish, and D. Kumar, "The correlation between colorectal cancer rates of proliferation and apoptosis and systemic cytokine levels; plus their influence upon survival," British journal of cancer, vol. 94, no. 10, pp. 1412-1419, 2006.

[112] R. J. O’Hara, J. Greenman, A. W. MacDonald, K. M. Gaskell, K. P. Topping, G. S. Duthie, M. J. Kerin, P. Lee, and J. Monson, "Advanced colorectal cancer is associated with impaired interleukin 12 and enhanced interleukin 10 production.," Clinical cancer research, vol. 4, no. 8, pp. 1943-1948, 1998.

[113] S. Abtahi, F. Davani, Z. Mojtahedi, S. V. Hosseini, A. Bananzadeh, A. Ghaderi, et al., "Dual association of serum interleukin-10 levels with colorectal cancer," Journal of Cancer Research and Therapeutics, vol. 13, no. 2, p. 252, 2017.

[114] S. Stanilova, N. Stanilov, A. Julianov, I. Manolova, and L. Miteva, "Transforming growth factor- $\beta 1$ gene promoter-509c/t polymorphism in association with expression affects colorectal cancer development and depends on gender," PloS one, vol. 13, no. 8, p. e0201775, 2018.

[115] C. Kosmidis, K. Sapalidis, T. Koletsa, M. Kosmidou, C. Efthimiadis, G. Anthimidis, N. Varsamis, N. Michalopoulos, C. Koulouris, S. Atmatzidis, et al., "Interferon- $\gamma$ and colorectal cancer: an up-to date," Journal of cancer, vol. 9, no. 2, p. 232, 2018.

[116] H. Enderling, "Integrating experimental data to calibrate quantitative cancer models," bioRxiv, p. 032102, 2015.

[117] R. Walker and H. Enderling, "A new paradigm for personalized cancer screening," BioRxiv, p. 265959, 2018.

[118] G. D. Grass, J. C. L. Alfonso, E. A. Welsh, K. Ahmed, J. Teer, L. B. Harrison, J. Cleveland, J. Mule, S. Eschrich, H. Enderling, et al., "Harnessing tumor immune ecosystem dynamics to personalize radiotherapy," bioRxiv, 2020.

[119] D. J. Glazar, G. D. Grass, J. A. Arrington, P. A. Forsyth, N. Raghunand, H.-H. M. $\mathrm{Yu}$, S. Sahebjam, and H. Enderling, "Tumor volume dynamics as an early biomarker for patient-specific evolution of resistance and progression in recurrent high-grade glioma," Journal of Clinical Medicine, vol. 9, no. 7, p. 2019, 2020.

[120] A. Voss and J. Voss, "A fast numerical algorithm for the estimation of diffusion model parameters," Journal of Mathematical Psychology, vol. 52, no. 1, pp. 1-9, 2008.

[121] C. Parra-Rojas and E. A. Hernandez-Vargas, "PDEparams: parameter fitting toolbox for partial differential equations in python," Bioinformatics, no. December, pp. 1-2, 2019.

[122] V. Vyshemirsky and M. Girolami, "BioBayes: A software package for Bayesian inference in systems biology," Bioinformatics, vol. 24, no. 17, pp. 1933-1934, 2008.

[123] X. Xun, J. Cao, B. Mallick, A. Maity, and R. J. Carroll, "Parameter Estimation of Partial Differential Equation Models," Journal of the American Statistical Association, vol. 108, pp. 1009-1020, sep 2013.

[124] W. Hao and A. Friedman, "The LDL-HDL Profile Determines the Risk of Atherosclerosis: A Mathematical Model," PLoS ONE, vol. 9, no. 3, p. e90497, 2014.

[125] J. Diao, E. Winter, C. Cantin, W. Chen, L. Xu, D. Kelvin, J. Phillips, and M. S. Cattral, "In Situ Replication of Immediate Dendritic Cell (DC) Precursors Contributes to Conventional DC Homeostasis in Lymphoid Tissue," The Journal of Immunology, vol. 176, pp. 7196-7206, jun 2006. 
bioRxiv preprint doi: https://doi org/10.1101/2020.11.02 365668; this version posted November 4, 2020. The copyright holder for this preprint (which was not certified by peer review) is the author/funder, who has granted bioRxiv a license to display the preprint in perpetuity. It is made available under aCC-BY-NC 4.0 International license.

[126] R. J. De Boer, D. Homann, and A. S. Perelson, "Different Dynamics of CD4 + and CD8 + T Cell Responses During and After Acute Lymphocytic Choriomeningitis Virus Infection," The Journal of Immunology, vol. 171, pp. 3928-3935, oct 2003.

[127] J. Day, A. Friedman, and L. S. Schlesinger, "Modeling the immune rheostat of macrophages in the lung in response to infection," Proceedings of the National Academy of Sciences, vol. 106, pp. 11246-11251, jul 2009.

[128] W. Hao and A. Friedman, "Mathematical model on Alzheimer's disease," BMC Systems Biology, vol. 10, p. 108, dec 2016.

[129] L. Zandarashvili, D. Sahu, K. Lee, Y. S. Lee, P. Singh, K. Rajarathnam, and J. Iwahara, "Real-time Kinetics of High-mobility Group Box 1 (HMGB1) Oxidation in Extracellular Fluids Studied by in Situ Protein NMR Spectroscopy," Journal of Biological Chemistry, vol. 288, pp. 11621-11627, apr 2013.

[130] T. Kuribayashi, "Elimination half-lives of interleukin-6 and cytokine-induced neutrophil chemoattractant-1 synthesized in response to inflammatory stimulation in rats," Laboratory Animal Research, vol. 34, no. 2, p. 80, 2018.

[131] D. L. Farber, N. A. Yudanin, and N. P. Restifo, "Human memory t cells: generation, compartmentalization and homeostasis," Nature Reviews Immunology, vol. 14, no. 1, pp. 24-35, 2014 .

[132] A. Saxena, S. Khosraviani, S. Noel, D. Mohan, T. Donner, and A. R. A. Hamad, "Interleukin-10 paradox: A potent immunoregulatory cytokine that has been difficult to harness for immunotherapy," Cytokine, vol. 74, no. 1, pp. 27-34, 2015.

[133] I. Fuentes-Calvo and C. Martínez-Salgado, "Tgfb1 (transforming growth factor, beta 1)," Atlas of Genetics and Cytogenetics in Oncology and Haematology, 2013.

[134] K. A. Foon, S. A. Sherwin, P. G. Abrams, H. C. Stevenson, P. Holmes, A. E. Maluish, R. K. Oldham, and R. B. Herberman, "A phase i trial of recombinant gamma interferon in patients with cancer," Cancer Immunology, Immunotherapy, vol. 20, no. 3, pp. 193-197, 1985 .

[135] M. Tada, F. Misaki, and K. Kawai, "Growth rates of colorectal carcinoma and adenoma by roentgenologic follow-up observations," Gastroenterologia Japonica, vol. 19, no. 6, pp. 550$555,1984$.

[136] F. Ginhoux and M. Guilliams, "Tissue-resident macrophage ontogeny and homeostasis," Immunity, vol. 44, no. 3, pp. 439-449, 2016. 


\section{Appendix A ODE system and analysis}

Combining equations (1)-(14) we obtain the following system

$$
\begin{aligned}
& \frac{d\left[T_{N}\right]}{d t}=A_{T_{N}}-\left(\lambda_{T_{h} D}[D]+\lambda_{T_{h} M}[M]+\lambda_{T_{h} \mu_{1}}\left[\mu_{1}\right]\right)\left[T_{N}\right]-\left(\lambda_{T_{C} T_{h}}\left[T_{h}\right]+\lambda_{T_{C} D}[D]\right)\left[T_{N}\right] \\
& -\left(\lambda_{T_{r} T_{h}}\left[T_{h}\right]+\lambda_{T_{r} \mu_{2}}\left[\mu_{2}\right]+\lambda_{T_{r} G_{\beta}}\left[G_{\beta}\right]\right)\left[T_{N}\right]-\delta_{T_{N}}\left[T_{N}\right] \\
& \frac{d\left[T_{h}\right]}{d t}=\left(\lambda_{T_{h} D}[D]+\lambda_{T_{h} M}[M]+\lambda_{T_{h} \mu_{1}}\left[\mu_{1}\right]\right)\left[T_{N}\right]-\left(\delta_{T_{h} \mu_{2}}\left[\mu_{2}\right]+\delta_{T_{h} T_{r}}\left[T_{r}\right]+\delta_{T_{h}}\right)\left[T_{h}\right] \\
& \frac{d\left[T_{C}\right]}{d t}=\left(\lambda_{T_{C} T_{h}}\left[T_{h}\right]+\lambda_{T_{C} D}[D]\right)\left[T_{N}\right]-\left(\delta_{T_{C} \mu_{2}}\left[\mu_{2}\right]+\delta_{T_{C} T_{r}}\left[T_{r}\right]+\delta_{T_{C}}\right)\left[T_{C}\right] \\
& \frac{d\left[T_{r}\right]}{d t}=\left(\lambda_{T_{r} T_{h}}\left[T_{h}\right]+\lambda_{T_{r} \mu_{2}}\left[\mu_{2}\right]+\lambda_{T_{r} G_{\beta}}\left[G_{\beta}\right]\right)\left[T_{N}\right]-\left(\delta_{T_{r} \mu_{1}}\left[\mu_{1}\right]+\delta_{T_{r}}\right)\left[T_{r}\right] \\
& \frac{d\left[D_{N}\right]}{d t}=A_{D_{N}}-\left(\lambda_{D H}[H]+\lambda_{D C}[C]\right)\left[D_{N}\right]-\left(\delta_{D H}[H]+\delta_{D}\right)\left[D_{N}\right] \\
& \frac{d[D]}{d t}=\left(\lambda_{D H}[H]+\lambda_{D C}[C]\right)\left[D_{N}\right]-\left(\delta_{D H}[H]+\delta_{D C}[C]+\delta_{D}\right)[D] \\
& \frac{d[M]}{d t}=\left(\lambda_{M \mu_{2}}\left[\mu_{2}\right]+\lambda_{M I_{\gamma}}\left[I_{\gamma}\right]+\lambda_{M T_{h}}\left[T_{h}\right]\right)\left(M_{0}-[M]\right)-\delta_{M}[M] \\
& \frac{d[C]}{d t}=\left(\lambda_{C}+\lambda_{C \mu_{1}}\left[\mu_{1}\right]\right)[C]\left(1-\frac{[C]}{C_{0}}\right)-\left(\delta_{C G_{\beta}}\left[G_{\beta}\right]+\delta_{C I_{\gamma}}\left[I_{\gamma}\right]+\delta_{C T_{C}}\left[T_{C}\right]+\delta_{C}\right)[C] \\
& \frac{d[N]}{d t}=\alpha_{N C}\left(\delta_{C G_{\beta}}\left[G_{\beta}\right]+\delta_{C I_{\gamma}}\left[I_{\gamma}\right]+\delta_{C T_{C}}\left[T_{C}\right]+\delta_{C}\right)[C]-\delta_{N}[N] \\
& \frac{d[H]}{d t}=\lambda_{H N}[N]+\lambda_{H M}[M]+\lambda_{H T_{h}}\left[T_{h}\right]+\lambda_{H T_{C}}\left[T_{C}\right]+\lambda_{H T_{r}}\left[T_{r}\right]-\delta_{H}[H] \\
& \frac{d\left[\mu_{1}\right]}{d t}=\lambda_{\mu_{1} T_{h}}\left[T_{h}\right]+\lambda_{\mu_{1} M}[M]+\lambda_{\mu_{1} D}[D]-\delta_{\mu_{1}}\left[\mu_{1}\right] \\
& \frac{d\left[\mu_{2}\right]}{d t}=\lambda_{\mu_{2} M}[M]+\lambda_{\mu_{2} D}[D]+\lambda_{\mu_{2} T_{r}}\left[T_{r}\right]-\delta_{\mu_{2}}\left[\mu_{2}\right] \\
& \frac{d\left[I_{\gamma}\right]}{d t}=\lambda_{I_{\gamma} T_{h}}\left[T_{h}\right]+\lambda_{I_{\gamma} T_{C}}\left[T_{C}\right]+\lambda_{I_{\gamma} M}[M]-\delta_{I_{\gamma}}\left[I_{\gamma}\right] \\
& \frac{d\left[G_{\beta}\right]}{d t}=\lambda_{G_{\beta} M}[M]+\lambda_{G_{\beta} T_{r}}\left[T_{r}\right]-\delta_{G_{\beta}}\left[G_{\beta}\right]
\end{aligned}
$$

The system has 14 variables and 59 different parameters. The $\lambda$ parameters correspond to proliferation, activation and production rates, $\delta$ parameters correspond to degradation and cell death rates, and four parameters: $A_{T_{N}}$ and $A_{D_{N}}$ respectively are the production rates of naive T-cells and dendritic cells, $M_{0}$ and $C_{0}$ are the total density of macrophages (naive and activated together) and cancer cells maximum capacity, respectively.

\section{Appendix A.1 Positivity}

To prove that the system with positive coefficients and positive initial conditions has positive solution let us consider the set of integrating factors, one for each variable:

$$
\begin{aligned}
& \eta_{T_{N}}(t)=\exp \int_{0}^{t}\left(\left(\lambda_{T_{h} D}+\lambda_{T_{c} D}\right)[D]+\lambda_{T_{h} M}[M]+\lambda_{T_{h} \mu_{1}}\left[\mu_{1}\right]+\right. \\
& \left.\quad+\left(\lambda_{T_{c} T_{h}}+\lambda_{T_{r} T_{h}}\right)\left[T_{h}\right]+\lambda_{T_{r} \mu_{2}}\left[\mu_{2}\right]+\lambda_{T_{r} G_{\beta}}\left[G_{\beta}\right]+\delta_{T_{N}}\right) d s \\
& \eta_{T_{h}}(t)=\exp \int_{0}^{t}\left(\delta_{T_{h} \mu_{2}}\left[\mu_{2}\right]+\delta_{T_{h} T_{r}}\left[T_{r}\right]+\delta_{T_{h}}\right) d s
\end{aligned}
$$




$$
\begin{aligned}
\eta_{T_{C}}(t) & =\exp \int_{0}^{t}\left(\delta_{T_{C} \mu_{2}}\left[\mu_{2}\right]+\delta_{T_{C} T_{r}}\left[T_{r}\right]+\delta_{T_{C}}\right) d s \\
\eta_{T_{r}}(t) & =\exp \int_{0}^{t}\left(\delta_{T_{r} \mu_{1}}\left[\mu_{1}\right]+\delta_{T_{r}}\right) d s \\
\eta_{D_{N}}(t) & =\exp \int_{0}^{t}\left(\lambda_{D H}[H]+\lambda_{D C}[C]+\delta_{D H}[H]+\delta_{D}\right) d s \\
\eta_{D}(t) & =\exp \int_{0}^{t}\left(\delta_{D H}[H]+\delta_{D C}[C]+\delta_{D}\right) d s, \\
\eta_{M}(t) & =\exp \int_{0}^{t}\left(\lambda_{M \mu_{2}}\left[\mu_{2}\right]+\lambda_{M I_{\gamma}}\left[I_{\gamma}\right]+\lambda_{M T_{h}}\left[T_{h}\right]+\delta_{M}\right) d s \\
\eta_{C}(t) & =\exp \int_{0}^{t}\left(\delta_{C G_{\beta}}\left[G_{\beta}\right]+\delta_{C I_{\gamma}}\left[I_{\gamma}\right]+\delta_{C T_{C}}\left[T_{C}\right]+\delta_{C}-\left(\lambda_{C}+\lambda_{C \mu_{1}}\left[\mu_{1}\right]\right)\left(1-\frac{[C]}{C_{0}}\right)\right) d s \\
\eta_{N}(t) & =\exp \left(\delta_{N} t\right), \quad \eta_{H}(t)=\exp \left(\delta_{H} t\right), \quad \eta_{\mu_{1}}(t)=\exp \left(\delta_{\mu_{1}} t\right), \\
\eta_{\mu_{2}}(t) & =\exp \left(\delta_{\mu_{2}} t\right), \quad \eta_{I_{\gamma}}(t)=\exp \left(\delta_{I_{\gamma}} t\right), \eta_{G_{\beta}}(t)=\exp \left(\delta_{G_{\beta}} t\right)
\end{aligned}
$$

These integrating factors will not allow us to derive explicit solution as some of them are defined through the unknown variables. But it is important to note that the factors are strictly positive and allow us to rewrite the system as

$$
\begin{aligned}
\frac{d\left(\left[T_{N}\right] \eta_{T_{N}}\right)}{d t} & =A_{T_{N}} \eta_{T_{N}} \\
\frac{d\left(\left[T_{h}\right] \eta_{T_{h}}\right)}{d t} & =\left(\lambda_{T_{h} D}[D]+\lambda_{T_{h} M}[M]+\lambda_{T_{h} \mu_{1}}\left[\mu_{1}\right]\right)\left[T_{N}\right] \eta_{T_{h}} \\
\frac{d\left(\left[T_{C}\right] \eta_{T_{C}}\right)}{d t} & =\left(\lambda_{T_{C} T_{h}}\left[T_{h}\right]+\lambda_{T_{C} D}[D]\right)\left[T_{N}\right] \eta_{T_{C}} \\
\frac{d\left(\left[T_{r}\right] \eta_{T_{r}}\right)}{d t} & =\left(\lambda_{T_{r} T_{h}}\left[T_{h}\right]+\lambda_{T_{r} \mu_{2}}\left[\mu_{2}\right]+\lambda_{T_{r} G_{\beta}}\left[G_{\beta}\right]\right)\left[T_{N}\right] \eta_{T_{r}} \\
\frac{d\left(\left[D_{N}\right] \eta_{D_{N}}\right)}{d t} & =A_{D_{N}} \eta_{D_{N}} \\
\frac{d\left([D] \eta_{D}\right)}{d t} & =\left(\lambda_{D H}[H]+\lambda_{D C}[C]\right)\left[D_{N}\right] \eta_{D} \\
\frac{d\left([M] \eta_{M}\right)}{d t} & =\left(\lambda_{M \mu_{2}}\left[\mu_{2}\right]+\lambda_{M I_{\gamma}}\left[I_{\gamma}\right]+\lambda_{M T_{h}}\left[T_{h}\right]\right) M_{0} \eta_{M} \\
\frac{d\left([C] \eta_{C}\right)}{d t} & =0 \\
\frac{d\left([N] \eta_{N}\right)}{d t} & =\alpha_{N C}\left(\delta_{C G_{\beta}}\left[G_{\beta}\right]+\delta_{C I_{\gamma}}\left[I_{\gamma}\right]+\delta_{C T_{C}}\left[T_{C}\right]+\delta_{C}\right)[C] \eta_{N} \\
\frac{d\left([H] \eta_{H}\right)}{d t} & =\left(\lambda_{H N}[N]+\lambda_{H M}[M]+\lambda_{H T_{h}}\left[T_{h}\right]+\lambda_{H T_{C}}\left[T_{C}\right]+\lambda_{H T_{r}}\left[T_{r}\right]\right) \eta_{H} \\
\frac{d\left(\left[\mu_{1}\right] \eta_{\mu_{1}}\right)}{d t} & =\left(\lambda_{\mu_{1} T_{h}}\left[T_{h}\right]+\lambda_{\mu_{1} M}[M]+\lambda_{\mu_{1} D}[D]\right) \eta_{\mu_{1}} \\
\frac{d\left(\left[\mu_{2}\right] \eta_{\mu_{2}}\right)}{d t} & =\left(\lambda_{\mu_{2} M}[M]+\lambda_{\mu_{2} D}[D]+\lambda_{\mu_{2} T_{r}}\left[T_{r}\right]\right) \eta_{\mu_{2}} \\
\frac{d\left(\left[I_{\gamma}\right] \eta_{I_{\gamma}}\right)}{d t} & =\left(\lambda_{I_{\gamma} T_{h}}\left[T_{h}\right]+\lambda_{I_{\gamma} T_{C}}\left[T_{C}\right]+\lambda_{I_{\gamma} M}[M]\right) \eta_{I_{\gamma}}
\end{aligned}
$$




$$
\frac{d\left(\left[G_{\beta}\right] \eta_{G_{\beta}}\right)}{d t}=\left(\lambda_{G_{\beta} M}[M]+\lambda_{G_{\beta} T_{r}}\left[T_{r}\right]\right) \eta_{G_{\beta}}
$$

We see that the right-hand side of each equation in this system is non-negative, which means that the variable-factor product is non-decreasing, and thus if positive initially remains positive at all times.

\section{Appendix A.2 Boundedness}

Let us show that all positive solutions are bounded for positive time $t$. We split the equations into groups by cell types. It is important to note, that we are not trying to derive the sharp bounds, just show that the bounds exist.

\section{T-cells}

Adding equations (15)-(18) we get

$$
\begin{aligned}
\frac{d\left(\left[T_{N}\right]+\left[T_{h}\right]+\left[T_{C}\right]+\left[T_{r}\right]\right)}{d t}= & A_{T_{N}}-\delta_{T_{N}}\left[T_{N}\right]-\left(\delta_{T_{h} \mu_{2}}\left[\mu_{2}\right]+\delta_{T_{h} T_{r}}\left[T_{r}\right]+\delta_{T_{h}}\right)\left[T_{h}\right] \\
& -\left(\delta_{T_{C} \mu_{2}}\left[\mu_{2}\right]+\delta_{T_{C} T_{r}}\left[T_{r}\right]+\delta_{T_{C}}\right)\left[T_{C}\right]-\left(\delta_{T_{r} \mu_{1}}\left[\mu_{1}\right]+\delta_{T_{r}}\right)\left[T_{r}\right] \\
\leq & A_{T_{N}}-\left(\left[T_{N}\right]+\left[T_{h}\right]+\left[T_{C}\right]+\left[T_{r}\right]\right) \min \left(\delta_{T_{N}}, \delta_{T_{h}}, \delta_{T_{C}}, \delta_{T_{r}}\right) .
\end{aligned}
$$

Integrating this inequality we obtain

$$
\begin{aligned}
\left(\left[T_{N}\right]+\left[T_{h}\right]+\left[T_{C}\right]+\left[T_{r}\right]\right) \leq & \frac{A_{T_{N}}}{\min \left(\delta_{T_{N}}, \delta_{T_{h}}, \delta_{T_{C}}, \delta_{T_{r}}\right)}\left(1-e^{-\min \left(\delta_{T_{N}}, \delta_{T_{h}}, \delta_{T_{C}}, \delta_{T_{r}}\right) t}\right) \\
& +\left(\left[T_{N}\right](0)+\left[T_{h}\right](0)+\left[T_{C}\right](0)+\left[T_{r}\right](0)\right) e^{-\min \left(\delta_{T_{N}}, \delta_{T_{h}}, \delta_{T_{C}}, \delta_{T_{r}}\right) t} .
\end{aligned}
$$

The right-hand side function is bounded, and since we have proven that each cell density is positive, all T-cells have to remain bounded.

\section{Dendritic cells}

Let us add equations (19) and (20) to obtain

$$
\frac{d\left(\left[D_{N}\right]+[D]\right)}{d t}=A_{D_{N}}-\left(\delta_{D H}[H]+\delta_{D}\right)\left(\left[D_{N}\right]+[D]\right)-\delta_{D C}[C][D] \leq A_{D_{N}}-\delta_{D}\left(\left[D_{N}\right]+[D]\right)
$$

Integrating we get

$$
\left(\left[D_{N}\right]+[D]\right) \leq \frac{A_{D_{N}}}{\delta_{D}}\left(1-e^{-\delta_{D} t}\right)+\left(\left[D_{N}\right](0)+[D](0)\right) e^{-\delta_{D} t} .
$$

Since right-hand side is bounded and each variable is positive, this proves that each variable is bounded.

\section{Macrophages}

Let us rewrite equation (21) as

$$
\frac{d\left([M]-M_{0}\right)}{d t}-\left(\lambda_{M \mu_{2}}\left[\mu_{2}\right]+\lambda_{M I_{\gamma}}\left[I_{\gamma}\right]+\lambda_{M T_{h}}\left[T_{h}\right]\right)\left(M_{0}-[M]\right)=-\delta_{M}[M] \leq 0 .
$$

Integrating (with implicit dependence on variables $\left[\mu_{2}\right],\left[I_{\gamma}\right]$, and $\left[T_{h}\right]$ ) results in

$$
[M] \leq M_{0}-\left(M_{0}-[M](0)\right) \exp \left(-\int_{0}^{t}\left(\lambda_{M \mu_{2}}\left[\mu_{2}\right](s)+\lambda_{M I_{\gamma}}\left[I_{\gamma}\right](s)+\lambda_{M T_{h}}\left[T_{h}\right](s)\right) d s\right) .
$$

The right-hand side function is bounded for positive $\left[\mu_{2}\right],\left[I_{\gamma}\right]$, and $\left[T_{h}\right]$, and thus proves the bound on $[M]$. 


\section{Cancer cells}

Rewriting the equation (22) as

$$
\frac{d\left([C]-C_{0}\right)}{d t}-\frac{\left(\lambda_{C}+\lambda_{C \mu_{1}}\left[\mu_{1}\right]\right)[C]}{C_{0}}\left(C_{0}-[C]\right)=\left(\delta_{C G_{\beta}}\left[G_{\beta}\right]+\delta_{C I_{\gamma}}\left[I_{\gamma}\right]+\delta_{C T_{C}}\left[T_{C}\right]+\delta_{C}\right)[C] \leq 0
$$

we integrate with implicit dependence on both $[C]$ and $\left[\mu_{1}\right]$ to obtain

$$
[C] \leq C_{0}-\left(C_{0}-[C](0)\right) \exp \left(-\int_{0}^{t} \frac{\left(\lambda_{C}+\lambda_{C \mu_{1}}\left[\mu_{1}\right](s)\right)[C](s)}{C_{0}} d s\right) .
$$

Since $[C]$ and $\left[\mu_{1}\right]$ are proven to remain positive, the right-hand side is bounded, hence $[C]$ is bounded.

\section{Interferon- $\gamma$ and TGF- $\beta$}

Here we show the bound on $\left[I_{\gamma}\right]$ and $\left[G_{\beta}\right]$ as we need them to prove the bound on $[N]$.

Remark. Alternatively we could show a bound on $\left[\mu_{1}\right]$ and subsequent bound on $[N]+[C]$.

Observe that in the right-hand sides of equations (27) and (28) the positive terms are already proven to be bounded:

$$
\begin{aligned}
\lambda_{I_{\gamma} T_{h}}\left[T_{h}\right]+\lambda_{I_{\gamma} T_{C}}\left[T_{C}\right]+\lambda_{I_{\gamma} M}[M] & \leq \lambda_{I_{\gamma}}^{\max } \\
\lambda_{G_{\beta} M}[M]+\lambda_{G_{\beta} T_{r}}\left[T_{r}\right] & \leq \lambda_{G_{\beta}}^{\max }
\end{aligned}
$$

Then combining these with equations (27) and (28) we get the following differential inequalities:

$$
\frac{d\left[I_{\gamma}\right]}{d t} \leq \lambda_{I_{\gamma}}^{\max }-\delta_{I_{\gamma}}\left[I_{\gamma}\right], \quad \frac{d\left[G_{\beta}\right]}{d t} \leq \lambda_{G_{\beta}}^{\max }-\delta_{G_{\beta}}\left[G_{\beta}\right] .
$$

Integrating we get

$$
\begin{gathered}
{\left[I_{\gamma}\right] \leq \frac{\lambda_{I_{\gamma}}^{\max }}{\delta_{I_{\gamma}}}\left(1-e^{-\delta_{I_{\gamma}} t}\right)+\left[I_{\gamma}\right](0) e^{-\delta_{I_{\gamma}} t},} \\
{\left[G_{\beta}\right] \leq \frac{\lambda_{G_{\beta}}^{\max }}{\delta_{G_{\beta}}}\left(1-e^{-\delta_{G_{\beta}} t}\right)+\left[G_{\beta}\right](0) e^{-\delta_{G_{\beta}} t},}
\end{gathered}
$$

which proves the bound.

\section{Necrotic cells}

Now we notice that for equation (23) all the components of the positive term are already proven to remain bounded

$$
\alpha_{N C}\left(\delta_{C G_{\beta}}\left[G_{\beta}\right]+\delta_{C I_{\gamma}}\left[I_{\gamma}\right]+\delta_{C T_{C}}\left[T_{C}\right]+\delta_{C}\right)[C] \leq \lambda_{N}^{\max },
$$

which results in the differential inequality

$$
\frac{d[N]}{d t} \leq \lambda_{N}^{\max }-\delta_{N}[N]
$$

subsequently resulting after integration in the following bound:

$$
[N] \leq \frac{\lambda_{N}^{\max }}{\delta_{N}}\left(1-e^{-\delta_{N} t}\right)+[N](0) e^{-\delta_{N} t}
$$




\section{Remaining cytokines}

With the bound on necrotic cells we have proven boundedness for all the positive components of the right-hand sides of the equations (24)-(26):

$$
\begin{aligned}
\lambda_{H N}[N]+\lambda_{H M}[M]+ & \lambda_{H T_{h}}\left[T_{h}\right]+\lambda_{H T_{C}}\left[T_{C}\right]+\lambda_{H T_{r}}\left[T_{r}\right] \leq \lambda_{H}^{\max }, \\
& \lambda_{\mu_{1} T_{h}}\left[T_{h}\right]+\lambda_{\mu_{1} M}[M]+\lambda_{\mu_{1} D}[D] \leq \lambda_{\mu_{1}}^{\max }, \\
& \lambda_{\mu_{2} M}[M]+\lambda_{\mu_{2} D}[D]+\lambda_{\mu_{2} T_{r}}\left[T_{r}\right] \leq \lambda_{\mu_{2}}^{\max }
\end{aligned}
$$

Thus the following differential inequalities are valid:

$$
\begin{aligned}
\frac{d[H]}{d t} & \leq \lambda_{H}^{\max }-\delta_{H}[H], \\
\frac{d\left[\mu_{1}\right]}{d t} & \leq \lambda_{\mu_{1}}^{\max }-\delta_{\mu_{1}}\left[\mu_{1}\right], \\
\frac{d\left[\mu_{2}\right]}{d t} & \leq \lambda_{\mu_{2}}^{\max }-\delta_{\mu_{2}}\left[\mu_{2}\right] .
\end{aligned}
$$

Integrating we obtain

$$
\begin{aligned}
& {[H] \leq \frac{\lambda_{H}^{\max }}{\delta_{H}}\left(1-e^{-\delta_{H} t}\right)+[H](0) e^{-\delta_{H} t},} \\
& {\left[\mu_{1}\right] \leq \frac{\lambda_{\mu_{1}}^{\max }}{\delta_{\mu_{1}}}\left(1-e^{-\delta_{\mu_{1}} t}\right)+\left[\mu_{1}\right](0) e^{-\delta_{\mu_{1}} t},} \\
& {\left[\mu_{2}\right] \leq \frac{\lambda_{\mu_{2}}^{\max }}{\delta_{\mu_{2}}}\left(1-e^{-\delta_{\mu_{2}} t}\right)+\left[\mu_{2}\right](0) e^{-\delta_{\mu_{2}} t} .}
\end{aligned}
$$

Thus $[H],\left[\mu_{1}\right]$, and $\left[\mu_{2}\right]$ are bounded for positive $t$.

\section{Appendix B Derivation of the sample parameter set}

\section{Appendix B.1 Steady state and additional assumptions}

We derive the sample parameter set under the assumption of specific values of steady state for each variable:

$$
T_{N}^{\infty}, T_{h}^{\infty}, T_{C}^{\infty}, T_{r}^{\infty}, D_{N}^{\infty}, D^{\infty}, M^{\infty}, C^{\infty}, N^{\infty}, H^{\infty}, \mu_{1}^{\infty}, \mu_{2}^{\infty}, I_{\gamma}^{\infty}, G_{\beta}^{\infty} .
$$

Then equations (15)-(28) provide us with 14 restrictions on parameters. There is a total of 59 parameters, so additional restrictions are required. We assume given cancer cell and macrophage capacities $C_{0}$ and $M_{0}$, as well as necrosis coefficient $\alpha_{N C}=3 / 4$. Additionally, from the available research $[107,125-134]$ we adopt the natural decay/death/degradation rates. For some of the specimen, considering a specimen $X$ we will estimate death rate $\delta_{X}$ using published measurements of half-life $t_{1 / 2}^{X}$ using the following formula $\delta_{X}=\ln 2 / t_{1 / 2}^{X}$. Other death rate estimates are provided directly in the referenced research. Here are the death rates used in our computations:

$$
\begin{aligned}
& \delta_{T_{n}}=9.4951 \cdot 10^{-4}, \quad \delta_{T_{h}}=0.231, \quad \delta_{T_{c}}=0.406, \quad \delta_{T_{r}}=0.231, \\
& \delta_{D}=0.277, \quad \delta_{M}=0.02, \quad \delta_{H}=58.7, \quad \delta_{I_{\gamma}}=33.27, \\
& \delta_{G_{\beta}}=499, \quad \delta_{\mu_{1}}=1.07, \quad \delta_{\mu_{2}}=4.62 \text {. }
\end{aligned}
$$

And as a last step, we impose heuristic assumptions on activation, inhibition and production rates. Let us look at these in detail.

First we consider the results in [135] suggesting that range of colon cancer doubling time is between 92.4 and 1032.2 days. Let us consider the doubling rate to be the difference between proliferation rate and death rate. Faster doubling rate includes both innate cancer proliferation 
and proliferation caused by $\mu_{1}$ family of cytokines, while death rate being only innate. This results in

$$
\frac{\ln 2}{92.4} \approx 7.5 \cdot 10^{-3}=\left(\lambda_{C}+\lambda_{C \mu_{1}} \mu_{1}^{\text {mean }}\right)-\delta_{C} .
$$

On the other hand for the slower doubling rate we only consider innate cancer proliferation, while death rate includes effects of all anti-cancer agents, i.e.

$$
\frac{\ln 2}{1032.2} \approx 6.7152 \cdot 10^{-4}=\lambda_{C}-\left(\delta_{C G_{\beta}} G_{\beta}^{\text {mean }}+\delta_{C I_{\gamma}} I_{\gamma}^{\text {mean }}+\delta_{C T_{C}} T_{C}^{\text {mean }}+\delta_{C}\right) .
$$

Here we consider $\mu_{1}^{\text {mean }}, T_{C}^{\text {mean }}, I_{\gamma}^{\text {mean }}$, and $G_{\beta}^{\text {mean }}$ to be average values of the corresponding variable across all patients.

Further assumptions are based on maximal observable quantities for all the variable across all patients:

$$
T_{N}^{\max }, T_{h}^{\max }, T_{C}^{\max }, T_{r}^{\max }, D_{N}^{\max }, D^{\max }, M^{\max }, C^{\max }, N^{\max }, H^{\max }, \mu_{1}^{\max }, \mu_{2}^{\max }, I_{\gamma}^{\max }, G_{\beta}^{\max } .
$$

See Appendix C for more details on patient data and specific values.

We assume that most of T-helper cells are activated by antigen-presenting dendritic cells, so we take

$$
\lambda_{T_{h} D} D^{\max }=200 \lambda_{T_{h} M} M^{\max }=200 \lambda_{T_{h} \mu_{1}} \mu_{1}^{\max } .
$$

We also assume that inhibition of T-helper cells by $\mu_{2}$ family of cytokines and by Treg cells are each 20 times more effective than the natural degradation:

$$
\delta_{T_{h} \mu_{2}} \mu_{2}^{\max }=\delta_{T_{h} T_{r}} T_{r}^{\max }=20 \delta_{T_{h}} .
$$

For cytotoxic T-cells we assume that activation by T-helper cells is twice as effective as activation by Dendritic cells

$$
\lambda_{T_{C} T_{h}} T_{h}^{\max }=2 \lambda_{T_{C} D} D^{\max },
$$

and same as for T-helper cells inhibition of cytotoxic T-cells by $\mu_{2}$ family of cytokines and by Treg cells are each 20 times more effective than the natural degradation:

$$
\delta_{T_{C} \mu_{2}} \mu_{2}^{\max }=\delta_{T_{C} T_{r}} T_{r}^{\max }=20 \delta_{T_{C}} .
$$

Next assumption is that activation of Treg cells by T-helper cells is four times larger than activation by $\mu_{2}$ family of cytokines and by TGF- $\beta$ :

$$
\lambda_{T_{r} T_{h}} T_{h}^{\max }=4 \lambda_{T_{r} G_{\beta}} G_{\beta}^{\max }, \quad \lambda_{T_{r} \mu_{2}} \mu_{2}^{\max }=\lambda_{T_{r} G_{\beta}} G_{\beta}^{\max },
$$

while inhibition of Treg cells by $\mu_{1}$ family of cytokines is 20 times larger than their natural degradation rate:

$$
\delta_{T_{r} \mu_{1}} \mu_{1}^{\max }=20 \delta_{T_{r}} .
$$

We impose that activation of dendritic cells by HMGB1 is twice more effective than activation by cancer cells, inhibition of dendritic cells by HMGB1 is twice less effective than inhibiiton by cancer cells, and cumulative inhibition of dendritic cells by HMGB1 and cancer cells is equivalent to the natural degradation rate of dendritic cells:

$$
\lambda_{D H} H^{\max }=2 \lambda_{D C} C^{\max }, \quad \delta_{D H} H^{\max }=\frac{1}{2} \delta_{D C} C^{\max }, \quad \delta_{D H} H^{\max }+\delta_{D C} C^{\max }=\delta_{D} .
$$

For macrophages we assume that most macrophages are activated by T-helper cells, thus

$$
\lambda_{M T_{h}} T_{h}^{\max }=10 \lambda_{M \mu_{2}} \mu_{2}^{\max }=10 \lambda_{M I_{\gamma}} I_{\gamma}^{\max } .
$$


Next we look at the cancer death rates. We assume TGF- $\beta$ and IFN- $\gamma$ equally effective in killing cancer cells, but cytotoxic T-cells to be twice more effective, so

$$
\delta_{C G_{\beta}} G_{\beta}^{\max }=\delta_{C I_{\gamma}} I_{\gamma}^{\max }=\frac{1}{2} \delta_{C T_{C}} T_{C}^{\max } .
$$

We also assume that at it's extreme value TGF- $\beta$ kills cancer cells 10 times faster than innate death rate of cancer cells:

$$
\delta_{C G_{\beta}} G_{\beta}^{\max }=10 \delta_{C} .
$$

Next let us list assumptions on production rates of cytokines per cell:

$$
\begin{array}{llrl}
\lambda_{\mu_{1} M}=4 \lambda_{\mu_{1} T_{h}}=8 \lambda_{\mu_{1} D}, & \lambda_{\mu_{2} D}=\lambda_{\mu_{2} M}=\lambda_{\mu_{2} T_{r}}, & \lambda_{H N}=10 \lambda_{H M}=20 \lambda_{H T_{h}}, \\
\lambda_{H T_{h}}=\lambda_{H T_{C}}=\lambda_{H T_{r}}, & \lambda_{I_{\gamma} T_{c}}=4 \lambda_{I_{\gamma} T_{h}}=20 \lambda_{I_{\gamma} M}, & \lambda_{G_{\beta} M}=\lambda_{G_{\beta} T_{r}} .
\end{array}
$$

Altogether these assumptions are sufficient to derive a sample parameter set.

\section{Appendix B.2 Non-dimensionalization}

For more stable numerical simulations and to avoid scale dependence in the sensitivity analysis, we introduce non-dimensional variables. For each variable $[X]$ with steady state $X^{\infty}$ we introduce non-dimensional $[X]=[X] / X^{\infty}$. Then for all the non-dimensional variables steady state will be equal to 1 . Because of the dramatic difference between timescales in different equations (related to natural decay rate) we make a choice to not scale time. Then we can rewrite the system as

$$
\begin{aligned}
& \frac{d\left[\bar{T}_{N}\right]}{d t}=\bar{A}_{T_{N}}-\alpha_{T_{N} T_{h}}\left(\bar{\lambda}_{T_{h} D}[\bar{D}]+\bar{\lambda}_{T_{h} M}[\bar{M}]+\bar{\lambda}_{T_{h} \mu_{1}}\left[\bar{\mu}_{1}\right]\right)\left[\bar{T}_{N}\right] \\
& -\alpha_{T_{N} T_{C}}\left(\bar{\lambda}_{T_{C} T_{h}}\left[\bar{T}_{h}\right]+\bar{\lambda}_{T_{C} D}[\bar{D}]\right)\left[\bar{T}_{N}\right] \\
& -\alpha_{T_{N} T_{r}}\left(\bar{\lambda}_{T_{r} T_{h}}\left[\bar{T}_{h}\right]+\bar{\lambda}_{T_{r} \mu_{2}}\left[\bar{\mu}_{2}\right]+\bar{\lambda}_{T_{r} G_{\beta}}\left[\bar{G}_{\beta}\right]\right)\left[\bar{T}_{N}\right]-\delta_{T_{N}}\left[\bar{T}_{N}\right] \\
& \frac{d\left[\bar{T}_{h}\right]}{d t}=\left(\bar{\lambda}_{T_{h} D}[\bar{D}]+\bar{\lambda}_{T_{h} M}[\bar{M}]+\bar{\lambda}_{T_{h} \mu_{1}}\left[\bar{\mu}_{1}\right]\right)\left[\bar{T}_{N}\right]-\left(\bar{\delta}_{T_{h} \mu_{2}}\left[\bar{\mu}_{2}\right]+\bar{\delta}_{T_{h} T_{r}}\left[\bar{T}_{r}\right]+\delta_{T_{h}}\right)\left[\bar{T}_{h}\right] \\
& \frac{d\left[\bar{T}_{C}\right]}{d t}=\left(\bar{\lambda}_{T_{C} T_{h}}\left[\bar{T}_{h}\right]+\bar{\lambda}_{T_{C} D}[\bar{D}]\right)\left[\bar{T}_{N}\right]-\left(\bar{\delta}_{T_{C} \mu_{2}}\left[\bar{\mu}_{2}\right]+\bar{\delta}_{T_{C} T_{r}}\left[\bar{T}_{r}\right]+\delta_{T_{C}}\right)\left[\bar{T}_{C}\right] \\
& \frac{d\left[\bar{T}_{r}\right]}{d t}=\left(\bar{\lambda}_{T_{r} T_{h}}\left[\bar{T}_{h}\right]+\bar{\lambda}_{T_{r} \mu_{2}}\left[\bar{\mu}_{2}\right]+\bar{\lambda}_{T_{r} G_{\beta}}\left[\bar{G}_{\beta}\right]\right)\left[\bar{T}_{N}\right]-\left(\bar{\delta}_{T_{r} \mu_{1}}\left[\bar{\mu}_{1}\right]+\delta_{T_{r}}\right)\left[\bar{T}_{r}\right] \\
& \frac{d\left[\bar{D}_{N}\right]}{d t}=\bar{A}_{D_{N}}-\alpha_{D_{N} D}\left(\bar{\lambda}_{D H}[\bar{H}]+\bar{\lambda}_{D C}[\bar{C}]\right)\left[\bar{D}_{N}\right]-\left(\bar{\delta}_{D H}[\bar{H}]+\delta_{D}\right)\left[\bar{D}_{N}\right] \\
& \frac{d[\bar{D}]}{d t}=\left(\bar{\lambda}_{D H}[\bar{H}]+\bar{\lambda}_{D C}[\bar{C}]\right)\left[\bar{D}_{N}\right]-\left(\bar{\delta}_{D H}[\bar{H}]+\bar{\delta}_{D C}[\bar{C}]+\delta_{D}\right)[\bar{D}] \\
& \frac{d[\bar{M}]}{d t}=\left(\bar{\lambda}_{M \mu_{2}}\left[\bar{\mu}_{2}\right]+\bar{\lambda}_{M I_{\gamma}}\left[\bar{I}_{\gamma}\right]+\bar{\lambda}_{M T_{h}}\left[\bar{T}_{h}\right]\right)\left(\bar{M}_{0}-[\bar{M}]\right)-\delta_{M}[\bar{M}] \\
& \frac{d[\bar{C}]}{d t}=\left(\lambda_{C}+\bar{\lambda}_{C \mu_{1}}\left[\bar{\mu}_{1}\right]\right)[\bar{C}]\left(1-\frac{[\bar{C}]}{\bar{C}_{0}}\right)-\left(\bar{\delta}_{C G_{\beta}}\left[\bar{G}_{\beta}\right]+\bar{\delta}_{C I_{\gamma}}\left[\bar{I}_{\gamma}\right]+\bar{\delta}_{C T_{C}}\left[\bar{T}_{C}\right]+\delta_{C}\right)[\bar{C}] \\
& \frac{d[\bar{N}]}{d t}=\bar{\alpha}_{N C}\left(\bar{\delta}_{C G_{\beta}}\left[\bar{G}_{\beta}\right]+\bar{\delta}_{C I_{\gamma}}\left[\bar{I}_{\gamma}\right]+\bar{\delta}_{C T_{C}}\left[\bar{T}_{C}\right]+\delta_{C}\right)[\bar{C}]-\delta_{N}[\bar{N}] \\
& \frac{d[H]}{d t}=\bar{\lambda}_{H N}[N]+\bar{\lambda}_{H M}[\bar{M}]+\bar{\lambda}_{H T_{h}}\left[\bar{T}_{h}\right]+\bar{\lambda}_{H T_{C}}\left[\bar{T}_{C}\right]+\bar{\lambda}_{H T_{r}}\left[\bar{T}_{r}\right]-\delta_{H}[\bar{H}] \\
& \frac{d\left[\bar{\mu}_{1}\right]}{d t}=\bar{\lambda}_{\mu_{1} T_{h}}\left[\bar{T}_{h}\right]+\bar{\lambda}_{\mu_{1} M}[M]+\bar{\lambda}_{\mu_{1} D}[\bar{D}]-\delta_{\mu_{1}}\left[\bar{\mu}_{1}\right]
\end{aligned}
$$




$$
\begin{aligned}
\frac{d\left[\bar{\mu}_{2}\right]}{d t} & =\bar{\lambda}_{\mu_{2} M}[\bar{M}]+\bar{\lambda}_{\mu_{2} D}[\bar{D}]+\bar{\lambda}_{\mu_{2} T_{r}}\left[\bar{T}_{r}\right]-\delta_{\mu_{2}}\left[\bar{\mu}_{2}\right] \\
\frac{d\left[\bar{I}_{\gamma}\right]}{d t} & =\bar{\lambda}_{I_{\gamma} T_{h}}\left[\bar{T}_{h}\right]+\bar{\lambda}_{I_{\gamma} T_{C}}\left[\bar{T}_{C}\right]+\bar{\lambda}_{I_{\gamma} M}[\bar{M}]-\delta_{I_{\gamma}}\left[\bar{I}_{\gamma}\right] \\
\frac{d\left[\bar{G}_{\beta}\right]}{d t} & =\bar{\lambda}_{G_{\beta} M}[\bar{M}]+\bar{\lambda}_{G_{\beta} T_{r}}\left[\bar{T}_{r}\right]-\delta_{G_{\beta}}\left[\bar{G}_{\beta}\right]
\end{aligned}
$$

where the nondimensional parameters can be expressed as follows:

$$
\begin{aligned}
& \bar{A}_{T_{N}}=\frac{A_{T_{N}}}{T_{N}^{\infty}}, \\
& \alpha_{T_{N} T_{h}}=\frac{T_{h}^{\infty}}{T_{N}^{\infty}}, \\
& \alpha_{T_{N} T_{C}}=\frac{T_{C}^{\infty}}{T_{N}^{\infty}}, \\
& \alpha_{T_{N} T_{r}}=\frac{T_{r}^{\infty}}{T_{N}^{\infty}}, \\
& \bar{A}_{D_{N}}=\frac{A_{D_{N}}}{D_{N}^{\infty}}, \\
& \alpha_{D_{N} D}=\frac{D^{\infty}}{D_{N}^{\infty}}, \\
& \bar{M}_{0}=\frac{M_{0}}{M^{\infty}}, \\
& \bar{C}_{0}=\frac{C_{0}}{C^{\infty}}, \\
& \bar{\alpha}_{N C}=\alpha_{N C} \frac{C^{\infty}}{N^{\infty}}, \\
& \bar{\lambda}_{T_{h} D}=\frac{\lambda_{T_{h} D} D^{\infty} T_{N}^{\infty}}{T_{h}^{\infty}}, \\
& \bar{\lambda}_{T_{h} M}=\frac{\lambda_{T_{h} M} M^{\infty} T_{N}^{\infty}}{T_{h}^{\infty}}, \quad \bar{\lambda}_{T_{h} \mu_{1}}=\frac{\lambda_{T_{h} \mu_{1}} \mu_{1}^{\infty} T_{N}^{\infty}}{T_{h}^{\infty}}, \\
& \bar{\lambda}_{T_{C} T_{h}}=\frac{\lambda_{T_{C} T_{h}} T_{h}^{\infty} T_{N}^{\infty}}{T_{C}^{\infty}}, \quad \bar{\lambda}_{T_{C} D}=\frac{\lambda_{T_{C} D} D^{\infty} T_{N}^{\infty}}{T_{C}^{\infty}} \\
& \bar{\lambda}_{T_{r} T_{h}}=\frac{\lambda_{T_{r} T_{h}} T_{h}^{\infty} T_{N}^{\infty}}{T_{r}^{\infty}}, \quad \bar{\lambda}_{T_{r} \mu_{2}}=\frac{\lambda_{T_{r} \mu_{2}} \mu_{2}^{\infty} T_{N}^{\infty}}{T_{r}^{\infty}}, \\
& \bar{\lambda}_{T_{r} G_{\beta}}=\frac{\lambda_{T_{r} G_{\beta}} G_{\beta}^{\infty} T_{N}^{\infty}}{T_{r}^{\infty}} \\
& \bar{\lambda}_{D H}=\frac{\lambda_{D H} H^{\infty} D_{N}^{\infty}}{D^{\infty}}, \\
& \bar{\lambda}_{D C}=\frac{\lambda_{D H} C^{\infty} D_{N}^{\infty}}{D^{\infty}} \\
& \bar{\lambda}_{M \mu_{2}}=\lambda_{M \mu_{2}} \mu_{2}^{\infty}, \\
& \bar{\lambda}_{M I_{\gamma}}=\lambda_{M I_{\gamma}} I_{\gamma}^{\infty}, \\
& \bar{\lambda}_{M T_{h}}=\lambda_{M T_{h}} T_{h}^{\infty}, \\
& \bar{\lambda}_{C \mu_{1}}=\lambda_{C \mu_{1}} \mu_{1}^{\infty}, \\
& \bar{\lambda}_{H N}=\frac{\lambda_{H N} N^{\infty}}{H^{\infty}}, \\
& \bar{\lambda}_{H M}=\frac{\lambda_{H M} M^{\infty}}{H^{\infty}}, \\
& \bar{\lambda}_{H T_{h}}=\frac{\lambda_{H T_{h}} T_{h}^{\infty}}{H^{\infty}}, \\
& \bar{\lambda}_{H T_{C}}=\frac{\lambda_{H T_{C} T_{C}^{\infty}}}{H^{\infty}}, \\
& \bar{\lambda}_{H T_{r}}=\frac{\lambda_{H T_{r}} T_{r}^{\infty}}{H^{\infty}}, \\
& \bar{\lambda}_{\mu_{1} T_{h}}=\frac{\lambda_{\mu_{1} T_{h} T_{h}^{\infty}}}{\mu_{1}^{\infty}}, \\
& \bar{\lambda}_{\mu_{1} M}=\frac{\lambda_{\mu_{1} M} M^{\infty}}{\mu_{1}^{\infty}}, \\
& \bar{\lambda}_{\mu_{1} D}=\frac{\lambda_{\mu_{1} D} D^{\infty}}{\mu_{1}^{\infty}}, \\
& \bar{\lambda}_{\mu_{2} M}=\frac{\lambda_{\mu_{2} M} M^{\infty}}{\mu_{2}^{\infty}}, \\
& \bar{\lambda}_{\mu_{2} D}=\frac{\lambda_{\mu_{2} D} D^{\infty}}{\mu_{2}^{\infty}}, \\
& \bar{\lambda}_{\mu_{2} T_{r}}=\frac{\lambda_{\mu_{2} T_{r}} T_{r}^{\infty}}{\mu_{2}^{\infty}}, \\
& \bar{\lambda}_{I_{\gamma} T_{h}}=\frac{\lambda_{I_{\gamma} T_{h}} T_{h}^{\infty}}{I_{\gamma}^{\infty}}, \\
& \bar{\lambda}_{I_{\gamma} T_{C}}=\frac{\lambda_{I_{\gamma} T_{C} T_{C}^{\infty}}}{I_{\gamma}^{\infty}}, \\
& \bar{\lambda}_{I_{\gamma} M}=\frac{\lambda_{I_{\gamma} M} M^{\infty}}{I_{\gamma}^{\infty}}, \\
& \bar{\lambda}_{G_{\beta} M}=\frac{\lambda_{G_{\beta} M} M^{\infty}}{G_{\beta}^{\infty}}, \\
& \bar{\lambda}_{G_{\beta} T_{r}}=\frac{\lambda_{G_{\beta} T_{r}} T_{r}^{\infty}}{G_{\beta}^{\infty}}, \\
& \bar{\delta}_{T_{h} \mu_{2}}=\delta_{T_{h} \mu_{2}} \mu_{2}^{\infty}, \\
& \bar{\delta}_{T_{h} T_{r}}=\delta_{T_{h} T_{r}} T_{r}^{\infty}, \\
& \bar{\delta}_{T_{C} \mu_{2}}=\delta_{T_{C} \mu_{2}} \mu_{2}^{\infty}, \\
& \bar{\delta}_{T_{C} T_{r}}=\delta_{T_{C} T_{r}} T_{r}^{\infty}, \\
& \bar{\delta}_{T_{r} \mu_{1}}=\delta_{T_{r} \mu_{1}} \mu_{1}^{\infty}, \\
& \bar{\delta}_{D H}=\delta_{D H} H^{\infty}, \\
& \bar{\delta}_{D C}=\delta_{D C} C^{\infty}, \\
& \bar{\delta}_{C G_{\beta}}=\delta_{C G_{\beta}} G_{\beta}^{\infty} \text {, } \\
& \bar{\delta}_{C I_{\gamma}}=\delta_{C I_{\gamma}} I_{\gamma}^{\infty},
\end{aligned}
$$

Cancer proliferation rate $\lambda_{C}$ and all the innate degradation/death rates remain unscaled.

Then the equations for doubling rate (32)-(33) become

$$
\begin{aligned}
\left(\lambda_{C}+\bar{\lambda}_{T_{h} \mu_{1}} \frac{\mu_{1}^{\text {mean }}}{\mu_{1}^{\infty}}\right)-\delta_{C} & =7.5 \cdot 10^{-3}, \\
\lambda_{C}-\left(\bar{\delta}_{C G_{\beta}} \frac{G_{\beta}^{\text {mean }}}{G_{\beta}^{\infty}}+\bar{\delta}_{C I_{\gamma}} \frac{I_{\gamma}^{\text {mean }}}{I_{\gamma}^{\infty}}+\bar{\delta}_{C T_{C}} \frac{T_{C}^{\text {mean }}}{T_{C}^{\infty}}+\delta_{C}\right) & =6.7152 \cdot 10^{-4},
\end{aligned}
$$

and the system of restrictions (34)-(44) in dimensionless form can be rewritten as

$$
\begin{array}{rlrl}
\bar{\lambda}_{T_{h} D} \frac{D^{\max }}{D^{\infty}} & =200 \bar{\lambda}_{T_{h}} M \frac{M^{\max }}{M^{\infty}}=200 \bar{\lambda}_{T_{h} \mu_{1}} \frac{\mu_{1}^{\max }}{\mu_{1}^{\infty}}, & & \bar{\delta}_{T_{h} \mu_{2}} \frac{\mu_{2}^{\max }}{\mu_{2}^{\infty}}=\bar{\delta}_{T_{h} T_{r}} \frac{T_{r}^{\max }}{T_{r}^{\infty}}=20 \bar{\delta}_{T_{h}}, \\
\bar{\lambda}_{T_{C} T_{h}} \frac{T_{h}^{\max }}{T_{h}^{\infty}}=2 \bar{\lambda}_{T_{C} D} \frac{D^{\max }}{D^{\infty}}, & \bar{\delta}_{T_{C} \mu_{2}} \frac{\mu_{2}^{\max }}{\mu_{2}^{\infty}}=\bar{\delta}_{T_{C} T_{r}} \frac{T_{r}^{\max }}{T_{r}^{\infty}}=20 \bar{\delta}_{T_{C}}, \\
\bar{\lambda}_{T_{r} T_{h}} \frac{T_{h}^{\max }}{T_{h}^{\infty}}=4 \bar{\lambda}_{T_{r} G_{\beta}} \frac{G_{\beta}^{\max }}{G_{\beta}^{\infty}}, & \bar{\lambda}_{T_{r} \mu_{2}} \frac{\mu_{2}^{\max }}{\mu_{2}^{\infty}}=\bar{\lambda}_{T_{r} G_{\beta}} \frac{G_{\beta}^{\max }}{G_{\beta}^{\infty}}, \\
\bar{\delta}_{T_{r} \mu_{1} \frac{\mu_{1}^{\max }}{\mu_{1}^{\infty}}}=20 \bar{\delta}_{T_{r}}, & \bar{\lambda}_{D H} \frac{H^{\max }}{H^{\infty}}=2 \bar{\lambda}_{D C} \frac{C^{\max }}{C^{\infty}},
\end{array}
$$




$$
\begin{aligned}
\bar{\delta}_{D H} \frac{H^{\max }}{H^{\infty}} & =\frac{1}{2} \bar{\delta}_{D C} \frac{C^{\max }}{C^{\infty}}=\frac{1}{3} \bar{\delta}_{D}, \\
\bar{\delta}_{C G_{\beta}} \frac{G_{\beta}^{\max }}{G_{\beta}^{\infty}} & =10 \delta_{C} \\
\frac{\bar{\lambda}_{\mu_{1} M}}{M^{\infty}} & =4 \frac{\bar{\lambda}_{\mu_{1} T_{h}}}{T_{h}^{\infty}}=8 \frac{\bar{\lambda}_{\mu_{1} D}}{D^{\infty}}, \\
\frac{\bar{\lambda}_{H N}}{N^{\infty}} & =10 \frac{\bar{\lambda}_{H M}}{M^{\infty}}=20 \frac{\bar{\lambda}_{H T_{h}}}{T_{h}^{\infty}}, \\
\frac{\bar{\lambda}_{I_{\gamma} T_{C}}}{T_{C}^{\infty}} & =4 \frac{\bar{\lambda}_{I_{\gamma} T_{h}}}{T_{h}^{\infty}}=20 \frac{\bar{\lambda}_{I_{\gamma} M}}{M^{\infty}},
\end{aligned}
$$$$
\bar{\lambda}_{M T_{h}} \frac{T_{h}^{\max }}{T_{h}^{\infty}}=10 \bar{\lambda}_{M \mu_{2}} \frac{\mu_{2}^{\max }}{\mu_{2}^{\infty}}=10 \bar{\lambda}_{M I_{\gamma}} \frac{I_{\gamma}^{\max }}{I_{\gamma}^{\infty}},
$$$$
\bar{\delta}_{C G_{\beta}} \frac{G_{\beta}^{\max }}{G_{\beta}^{\infty}}=\bar{\delta}_{C I_{\gamma}} \frac{I_{\gamma}^{\max }}{I_{\gamma}^{\infty}}=\frac{1}{2} \bar{\delta}_{C T_{C}} \frac{T_{C}^{\max }}{T_{C}^{\infty}},
$$$$
\frac{\bar{\lambda}_{\mu_{2} D}}{D^{\infty}}=\frac{\bar{\lambda}_{\mu_{2} M}}{M^{\infty}}=\frac{\bar{\lambda}_{\mu_{2} T_{r}}}{T_{r}^{\infty}},
$$$$
\frac{\bar{\lambda}_{H T_{h}}}{T_{h}^{\infty}}=\frac{\bar{\lambda}_{H T_{C}}}{T_{C}^{\infty}}=\frac{\bar{\lambda}_{H T_{r}}}{T_{r}^{\infty}},
$$$$
\frac{\bar{\lambda}_{G_{\beta} M}}{M^{\infty}}=\frac{\bar{\lambda}_{G_{\beta} T_{r}}}{T_{r}^{\infty}} .
$$

These 29 restriction, together with 14 equations from requiring steady state of (45)-(58), and 11 given decay rates (29)-(31), scaling coefficients

$$
\alpha_{T_{N} T_{h}}=\frac{T_{h}^{\infty}}{T_{N}^{\infty}}, \quad \alpha_{T_{N} T_{C}}=\frac{T_{C}^{\infty}}{T_{N}^{\infty}}, \quad \alpha_{T_{N} T_{r}}=\frac{T_{r}^{\infty}}{T_{N}^{\infty}}, \quad \alpha_{D_{N} D}=\frac{D^{\infty}}{D_{N}^{\infty}}, \quad \bar{\alpha}_{N C}=\alpha_{N C} \frac{C^{\infty}}{N^{\infty}},
$$

and given $\alpha_{N C}, \bar{C}_{0}$ and $\bar{M}_{0}$ are enough to derive all 63 non-dimensional coefficients of (45)-(58) from

$$
T_{N}^{\infty}, T_{h}^{\infty}, T_{C}^{\infty}, T_{r}^{\infty}, D_{N}^{\infty}, D^{\infty}, M^{\infty}, C^{\infty}, N^{\infty}, H^{\infty}, \mu_{1}^{\infty}, \mu_{2}^{\infty}, I_{\gamma}^{\infty}, G_{\beta}^{\infty} .
$$

\section{Appendix B.3 Parameter values}

Here we detail all the parameter values derived and used in this paper. We divide them into three groups: innate degradation rates derived or adopted from prior research (see Table A1), scaling-independent parameters (those not affected by non-dimensionalization, see Table A2), and scaling-dependent parameters (see Table A3).

Table A1: Prescribed parameters and their references. Innate degradation and death rates $\left(\right.$ in day ${ }^{-1}$ ) derived or adopted from given references.

\begin{tabular}{lccccccccccc}
\hline Parameter & $\delta_{T_{N}}$ & $\delta_{T_{h}}$ & $\delta_{T_{C}}$ & $\delta_{T_{r}}$ & $\delta_{D}$ & $\delta_{M}$ & $\delta_{\mu_{1}}$ & $\delta_{\mu_{2}}$ & $\delta_{H}$ & $\delta_{I_{\gamma}}$ & $\delta_{G_{\beta}}$ \\
\hline Value & $9.4951 \mathrm{e}-4$ & 0.231 & 0.406 & 0.231 & 0.277 & 0.02 & 1.07 & 4.62 & 58.7 & 33.27 & 499.0 \\
\hline Reference & {$[131]$} & {$[126]$} & {$[126]$} & {$[126]$} & {$[125]$} & {$[127,136]$} & {$[130]$} & {$[132]$} & {$[129]$} & {$[134]$} & {$[133]$} \\
\hline
\end{tabular}

Table A2: Scaling-independent parameters. Values of scaling-independent parameters (in day $^{-1}$ ) for each cluster derived from the steady state assumptions and patient data.

\begin{tabular}{llllll}
\hline parameter & Cluster 1 & Cluster 2 & Cluster 3 & Cluster 4 & Cluster 5 \\
\hline$\lambda_{C}$ & $5.3323 \mathrm{e}-3$ & $3.7596 \mathrm{e}-3$ & $7.8327 \mathrm{e}-3$ & $5.3535 \mathrm{e}-3$ & $5.5150 \mathrm{e}-3$ \\
$\delta_{C}$ & $7.8626 \mathrm{e}-4$ & $5.2094 \mathrm{e}-4$ & $1.2081 \mathrm{e}-3$ & $7.8983 \mathrm{e}-4$ & $8.1708 \mathrm{e}-4$ \\
$\delta_{N}$ & $6.7332 \mathrm{e}-3$ & $7.0593 \mathrm{e}-3$ & $6.8602 \mathrm{e}-3$ & $5.9142 \mathrm{e}-3$ & $6.0514 \mathrm{e}-3$ \\
\hline
\end{tabular}

The scaling-independent parameters parameters include innate cancer proliferation rate $\lambda_{C}$, innate cancer death rate (including apoptosis and necrosis) $\delta_{C}$, and necrotic cell degradation rate $\delta_{N}$. Because these parameters were not affected by non-dimensionalization procedure, as they are determined they remain independent of the scaling constant $\alpha_{\text {dim }}$, and depend solely on the derivation assumptions and patient data (thus different between clusters).

The scaling dependent parameters in their dimensional form in addition to derivation assumptions and patient data would also depend on the scaling constant $\alpha_{\text {dim }}$. Thus we prefer 
Table A3: Scaling-dependent parameters. Non-dimensional values of scaling-dependent parameters (in day ${ }^{-1}$, because the time was not scaled) for each cluster derived from the steady state assumptions and patient data.

\begin{tabular}{|c|c|c|c|c|c|}
\hline Parameter & Cluster 1 & Cluster 2 & Cluster 3 & Cluster 4 & Cluster 5 \\
\hline $\bar{\lambda}_{T_{h} D}$ & 2.1399 & 2.7619 & 2.3163 & 1.7613 & 2.0179 \\
\hline $\bar{\lambda}_{T_{h} M}$ & $3.9171 \mathrm{e}-2$ & $4.3371 \mathrm{e}-2$ & 7.8933e-2 & $3.4235 \mathrm{e}-2$ & $1.1462 \mathrm{e}-1$ \\
\hline $\bar{\lambda}_{T_{h} \mu_{1}}$ & $1.1871 \mathrm{e}-2$ & $1.9332 \mathrm{e}-2$ & $5.0516 \mathrm{e}-2$ & $6.6146 \mathrm{e}-3$ & $2.6083 \mathrm{e}-2$ \\
\hline $\bar{\lambda}_{T_{C} T_{h}}$ & 3.2503 & 4.4295 & 3.6087 & 2.3377 & 3.5400 \\
\hline $\bar{\lambda}_{T_{C} D}$ & $6.0053 \mathrm{e}-1$ & $5.3505 \mathrm{e}-1$ & $6.8998 \mathrm{e}-1$ & $8.2970 \mathrm{e}-1$ & $2.5392 \mathrm{e}-1$ \\
\hline $\bar{\lambda}_{T_{r} T_{h}}$ & $8.2898 \mathrm{e}-1$ & $8.9260 \mathrm{e}-1$ & $7.1048 \mathrm{e}-1$ & $6.6821 \mathrm{e}-1$ & $6.4634 \mathrm{e}-1$ \\
\hline $\bar{\lambda}_{T_{r} \mu_{2}}$ & $5.1120 \mathrm{e}-2$ & $4.3090 \mathrm{e}-2$ & $1.4558 \mathrm{e}-1$ & $1.9891 \mathrm{e}-2$ & $2.6898 \mathrm{e}-2$ \\
\hline $\bar{\lambda}_{T_{r} G_{\beta}}$ & $6.4120 \mathrm{e}-2$ & $6.1990 \mathrm{e}-2$ & $2.4271 \mathrm{e}-1$ & $4.1296 \mathrm{e}-2$ & $8.4474 \mathrm{e}-2$ \\
\hline $\bar{\lambda}_{D H}$ & $2.6134 \mathrm{e}-1$ & $2.5410 \mathrm{e}-1$ & $2.6749 \mathrm{e}-1$ & $2.0531 \mathrm{e}-1$ & $2.5253 \mathrm{e}-1$ \\
\hline $\bar{\lambda}_{D C}$ & $1.0129 \mathrm{e}-1$ & $1.0998 \mathrm{e}-1$ & $9.6275 \mathrm{e}-2$ & $1.4619 \mathrm{e}-1$ & $9.9406 \mathrm{e}-2$ \\
\hline $\bar{\lambda}_{M \mu_{2}}$ & $6.0389 \mathrm{e}-4$ & $4.0918 \mathrm{e}-4$ & $4.0357 \mathrm{e}-4$ & $1.0688 \mathrm{e}-3$ & $2.2488 \mathrm{e}-4$ \\
\hline $\bar{\lambda}_{M I_{\gamma}}$ & $5.4536 \mathrm{e}-4$ & $4.4647 \mathrm{e}-4$ & $3.5449 \mathrm{e}-5$ & $5.5129 \mathrm{e}-4$ & $2.4891 \mathrm{e}-4$ \\
\hline $\bar{\lambda}_{M T_{h}}$ & $2.4482 \mathrm{e}-2$ & $2.1190 \mathrm{e}-2$ & $4.9239 \mathrm{e}-3$ & $8.9758 \mathrm{e}-2$ & $1.3509 \mathrm{e}-2$ \\
\hline $\bar{\lambda}_{C \mu_{1}}$ & $3.6453 \mathrm{e}-3$ & $5.6528 \mathrm{e}-3$ & $1.3143 \mathrm{e}-3$ & $2.5321 \mathrm{e}-3$ & $2.5536 \mathrm{e}-3$ \\
\hline $\bar{\alpha}_{N C}$ & 1.5 & 1.5 & 1.5 & 1.5 & 1.5 \\
\hline $\bar{\lambda}_{\mu_{1} T_{h}}$ & $9.5154 \mathrm{e}-2$ & $1.5848 \mathrm{e}-1$ & $5.1746 \mathrm{e}-2$ & $4.8884 \mathrm{e}-2$ & $8.0520 \mathrm{e}-2$ \\
\hline $\bar{\lambda}_{\mu_{1} M}^{\mu_{1} n}$ & $9.6867 \mathrm{e}-1$ & $9.0479 \mathrm{e}-1$ & 1.0148 & 1.0150 & $9.8745 \mathrm{e}-1$ \\
\hline $\bar{\lambda}_{\mu_{1} D}^{\mu_{1}}$ & $6.1798 \mathrm{e}-3$ & $6.7287 \mathrm{e}-3$ & $3.4777 \mathrm{e}-3$ & $6.0984 \mathrm{e}-3$ & $2.0302 \mathrm{e}-3$ \\
\hline $\bar{\lambda}_{\mu_{2} M}$ & 3.6856 & 3.1869 & 3.2127 & 3.7737 & 3.7140 \\
\hline $\bar{\lambda}_{\mu_{2} D}$ & $1.8810 \mathrm{e}-1$ & $1.8960 \mathrm{e}-1$ & 8.8081e-2 & $1.8139 \mathrm{e}-1$ & $6.1088 \mathrm{e}-2$ \\
\hline $\bar{\lambda}_{\mu_{2} T_{r}}$ & $7.4634 \mathrm{e}-1$ & 1.2435 & 1.3192 & $6.6490 \mathrm{e}-1$ & $8.4487 \mathrm{e}-1$ \\
\hline $\bar{\lambda}_{H N}$ & $5.6645 \mathrm{e}+1$ & $5.6824 \mathrm{e}+1$ & $5.7494 \mathrm{e}+1$ & $5.6720 \mathrm{e}+1$ & $5.6504 \mathrm{e}+1$ \\
\hline $\bar{\lambda}_{H M}$ & 1.4603 & 1.0096 & $8.6817 \mathrm{e}-1$ & 1.5130 & 1.6271 \\
\hline $\bar{\lambda}_{H T_{h}}$ & $2.8689 \mathrm{e}-1$ & $3.5366 \mathrm{e}-1$ & $8.8539 \mathrm{e}-2$ & $1.4573 \mathrm{e}-1$ & $2.6536 \mathrm{e}-1$ \\
\hline $\bar{\lambda}_{H T_{C}}$ & $1.5995 \mathrm{e}-1$ & $3.1527 \mathrm{e}-1$ & $7.1133 \mathrm{e}-2$ & $1.8821 \mathrm{e}-1$ & $1.1817 \mathrm{e}-1$ \\
\hline $\bar{\lambda}_{H T_{r}}$ & $1.4786 \mathrm{e}-1$ & $1.9697 \mathrm{e}-1$ & $1.7824 \mathrm{e}-1$ & $1.3328 \mathrm{e}-1$ & $1.8507 \mathrm{e}-1$ \\
\hline $\bar{\lambda}_{I_{\gamma} T_{h}}$ & 8.8980 & 6.8580 & 6.4053 & 4.6181 & 9.8011 \\
\hline $\bar{\lambda}_{I_{\gamma} T_{C}}$ & $1.9843 \mathrm{e}+1$ & $2.4454 \mathrm{e}+1$ & $2.0584 \mathrm{e}+1$ & $2.3857 \mathrm{e}+1$ & $1.7459 \mathrm{e}+1$ \\
\hline $\bar{\lambda}_{I_{\gamma} M}$ & 4.5290 & 1.9577 & 6.2806 & 4.7945 & 6.0098 \\
\hline $\bar{\lambda}_{G_{\beta} M}$ & $4.1497 \mathrm{e}+2$ & $3.5894 \mathrm{e}+2$ & $3.5375 \mathrm{e}+2$ & $4.2425 \mathrm{e}+2$ & $4.0652 \mathrm{e}+2$ \\
\hline $\bar{\lambda}_{G_{\beta} T_{r}}$ & $8.4033 \mathrm{e}+1$ & $1.4006 \mathrm{e}+2$ & $1.4525 \mathrm{e}+2$ & $7.4749 \mathrm{e}+1$ & $9.2476 \mathrm{e}+1$ \\
\hline $\bar{\delta}_{T_{h} \mu_{2}}$ & $4.2911 \mathrm{e}-1$ & $4.3775 \mathrm{e}-1$ & $4.2642 \mathrm{e}-1$ & $1.1131 \mathrm{e}-1$ & $2.3641 \mathrm{e}-1$ \\
\hline $\bar{\delta}_{T_{h} T_{r}}$ & 1.5309 & 2.1559 & 1.7884 & 1.4599 & 1.6912 \\
\hline $\bar{\delta}_{T_{C} \mu_{2}}$ & $7.5419 \mathrm{e}-1$ & $7.6938 \mathrm{e}-1$ & 7.4947e-1 & $1.9563 \mathrm{e}-1$ & $4.1550 \mathrm{e}-1$ \\
\hline $\bar{\delta}_{T_{C} T_{r}}$ & 2.6906 & 3.7891 & 3.1432 & 2.5658 & 2.9724 \\
\hline $\bar{\delta}_{T_{r} \mu_{1}}$ & $7.1322 \mathrm{e}-1$ & $7.6668 \mathrm{e}-1$ & $8.6777 \mathrm{e}-1$ & $4.9839 \mathrm{e}-1$ & $5.2671 \mathrm{e}-1$ \\
\hline $\bar{\delta}_{D H}$ & $3.3577 \mathrm{e}-2$ & $3.1883 \mathrm{e}-2$ & $3.5563 \mathrm{e}-2$ & $1.9360 \mathrm{e}-2$ & $2.9105 \mathrm{e}-2$ \\
\hline $\bar{\delta}_{D C}$ & $5.2053 \mathrm{e}-2$ & $5.5200 \mathrm{e}-2$ & $5.1199 \mathrm{e}-2$ & $5.5139 \mathrm{e}-2$ & $4.5828 \mathrm{e}-2$ \\
\hline $\bar{\delta}_{C G_{\beta}}$ & $9.1600 \mathrm{e}-4$ & 7.1011e-4 & $1.8590 \mathrm{e}-3$ & $3.9506 \mathrm{e}-4$ & $1.3131 \mathrm{e}-3$ \\
\hline $\bar{\delta}_{C I_{\gamma}}$ & $6.5951 \mathrm{e}-4$ & $5.3859 \mathrm{e}-4$ & $9.7944 \mathrm{e}-5$ & $9.8156 \mathrm{e}-5$ & $4.6278 \mathrm{e}-4$ \\
\hline $\bar{\delta}_{C T_{C}}$ & $2.1270 \mathrm{e}-3$ & $2.9365 \mathrm{e}-3$ & $1.4085 \mathrm{e}-3$ & $2.6597 \mathrm{e}-3$ & $1.4414 \mathrm{e}-3$ \\
\hline $\bar{A}_{T_{N}}$ & 1.5006 & 4.1268 & 1.2183 & 1.1785 & 1.6150 \\
\hline $\bar{A}_{D n}$ & 1.0264 & 2.1172 & $3.5941 \mathrm{e}+2$ & 1.8353 & 1.1435 \\
\hline $\bar{M}_{0}$ & 1.7803 & 1.9072 & 4.7293 & 1.2189 & 2.4303 \\
\hline $\bar{C}_{0}$ & 2.0 & 2.0 & 2.0 & 2.0 & 2.0 \\
\hline$\alpha_{T_{N} T_{h}}$ & $3.1084 \mathrm{e}-1$ & $5.2856 \mathrm{e}-1$ & $1.5008 \mathrm{e}-1$ & $1.7950 \mathrm{e}-1$ & $3.6879 \mathrm{e}-1$ \\
\hline$\alpha_{T_{N} T_{C}}$ & $1.7330 \mathrm{e}-1$ & $4.7118 \mathrm{e}-1$ & $1.2057 \mathrm{e}-1$ & $2.3182 \mathrm{e}-1$ & $1.6423 \mathrm{e}-1$ \\
\hline$\alpha_{T_{N} T_{r}}$ & $1.6020 \mathrm{e}-1$ & $2.9438 \mathrm{e}-1$ & $3.0212 \mathrm{e}-1$ & $1.6417 \mathrm{e}-1$ & $2.5720 \mathrm{e}-1$ \\
\hline$\alpha_{D_{N} D}$ & 1.9739 & 4.9667 & $9.8717 \mathrm{e}+2$ & 4.3783 & 2.3796 \\
\hline
\end{tabular}


to list their more objective non-dimensional values. Because non-dimensionalization was done without time scaling, the dimension of most of these parameters is day ${ }^{-1}$. Exceptions are $\bar{\alpha}_{N C}$, $\bar{M}_{0}, \bar{C}_{0}, \alpha_{T_{N} T_{h}}, \alpha_{T_{N} T_{C}}, \alpha_{T_{N} T_{r}}, \alpha_{D_{N} D}$, these are fully non-dimensional.

\section{Appendix C Patient data and initial conditions}

Here we describe the processing of the data to be used for parameter estimation and initial conditions. The clustered deconvolution data, described in section 2.3, and original TCGA data is used to calculate the immune variables as described in table A4.

Table A4: Patient data correspondence with variables. Correspondence between the system variables and the source data from TCGA and deconvolution results.

\begin{tabular}{ll}
\hline Variable & Data used \\
\hline$T_{N}$ & T cells CD4 naive, T cells CD4 memory resting, NK cells resting \\
$T_{h}$ & T cells CD4 memory activated, T cells follicular helper \\
$T_{C}$ & T cells CD8, NK cells activated \\
$T_{r}$ & T cells regulatory (Tregs) \\
$D_{N}$ & Dendritic cells resting \\
$D$ & Dendritic cells activated \\
$M$ & Macrophages M1, Macrophages M2 \\
$M_{0}$ & Monocytes, Macrophages M0, Macrophages M1, Macrophages \\
& M2 \\
$\mu_{1}$ & IL6, IL17A, IL17B, IL17C, IL17D, IL17F, IL21, IL22 \\
$\mu_{2}$ & CCL20, IL10 \\
$H$ & HMGB1 \\
$I_{\gamma}$ & IFNG \\
$G_{\beta}$ & TGFB1, TGFB1I1, TGFB2, TGFB3, TGFBI \\
size $(P)$ & multiply_dimensions \\
Total_Immune_Density & $T_{N}, T_{h}, T_{C}, T_{r}, D_{N}, D, M_{0}$ \\
\hline
\end{tabular}

For variables related to immune cells we substitute zero values with $10 \%$ of the smallest positive cell density for numerical stability.

We estimate the relative amount of cancer cells and necrotic cells as follows: we start by assuming that on average across all patients the ratio of immune cells:cancer cells:necrotic cells will be approximately 0.4:0.4:0.2 with variability between clusters based on tumor size. For patient $P$ we consider tumor size $(\operatorname{size}(P))$ to be the product of the longest dimension and the shortest dimension. We assume total cell density at the steady state to be proportional to this product as

$$
\text { Total_Cell_Density }_{P}=\alpha_{\operatorname{dim}} \frac{\operatorname{size}(P)}{\frac{1}{K} \sum_{\text {all } P} \operatorname{size}(P)} .
$$

Tumor deconvolution data only provides us with ratios of immune cells relative to each other. Thus, to properly adjust the scaling, we take each immune cell value from deconvolution multiplied by $0.4 \alpha_{d i m}$, and consider $0.4 \alpha_{\operatorname{dim}} \sum$ (Immune cell ratios) as total immune density and

$$
C=\frac{2}{3} \text { (Total_Cell_Density - Total_Immune_Density) }, \quad N=0.5 C .
$$

Next, for each cluster we divide patients into three groups according to their their tumor size: above average, below average and no data. Resulting patient numbers of each group are given in table A5. We use the means from the group "above average" as steady state assumptions given in table 2. 
bioRxiv preprint doi: https://doi.org/10.1101/2020.11.02.365668; this version posted November 4, 2020. The copyright holder for this preprint (which was not certified by peer review) is the author/funder, who has granted bioRxiv a license to display the preprint in perpetuity. It is made available under aCC-BY-NC 4.0 International license.

Table A5: Distribution of patients according to their tumor size. Evaluated relative to the average tumor size within each cluster.

\begin{tabular}{lccccc}
\hline & Cluster 1 & Cluster 2 & Cluster 3 & Cluster 4 & Cluster 5 \\
\hline Total patients & 114 & 47 & 29 & 40 & 98 \\
Above average & 36 & 15 & 7 & 17 & 36 \\
Below average & 48 & 20 & 12 & 23 & 44 \\
No data & 30 & 12 & 10 & 0 & 18 \\
\hline
\end{tabular}

The data in the "below average" group as evaluated by (59) may contain negative values for cancer and necrotic cells. The data in "no data" group has no values for cancer and necrotic cells. Thus we substitute all non-positive and absent cancer values with $10 \%$ of the smallest positive cancer density value. We substitute all non-positive and absent necrotic cell values with zero. These changes violate the 0.4:0.4:0.2 ratio of immune cells:cancer cells:necrotic cells, and the updated ratio is $0.4475: 0.3684: 0.1841$.

The steady state assumptions (see Appendix Appendix B) are partially based on maximum values of each variable in the ODE system (15)-(28) across all patients, as well as mean value of variables $T_{C}, \mu_{1}, I_{\gamma}$, and $G_{\beta}$ across all patients. The corresponding values are given in table A6.

Table A6: Maximum and mean variable values for parameter estimation. Maximum and mean cell densities in cells $/ \mathrm{cm}^{3}$ and cytokine expression levels across all patients used in appendix Appendix B to derive parameter sets for time-dependent solutions.

\begin{tabular}{cccccc}
\hline $\mathbf{T}_{\mathbf{N}}^{\max }$ & $\mathbf{T}_{\mathbf{h}}^{\max }$ & $\mathbf{T}_{\mathbf{C}}^{\max }$ & $\mathbf{T}_{\mathbf{r}}^{\max }$ & $\mathbf{D}_{\mathbf{N}}^{\max }$ & $\mathbf{D}^{\max }$ \\
\hline $2.6731 \mathrm{e}+4$ & $1.2311 \mathrm{e}+4$ & $1.9107 \mathrm{e}+4$ & $7.2102 \mathrm{e}+3$ & $3.4173 \mathrm{e}+3$ & $4.3275 \mathrm{e}+3$ \\
\hline $\mathbf{M}^{\max }$ & $\mathbf{C}^{\max }$ & $\mathbf{N}^{\max }$ & $\mu_{1}^{\max }$ & $\mu_{2}^{\max }$ & $\mathbf{H}^{\max }$ \\
\hline $2.3160 \mathrm{e}+4$ & $3.2472 \mathrm{e}+5$ & $1.6236 \mathrm{e}+5$ & $1.0577 \mathrm{e}+3$ & $1.3983 \mathrm{e}+4$ & $2.4697 \mathrm{e}+4$ \\
\hline $\mathbf{I}_{\gamma}^{\max }$ & $\mathbf{G}_{\beta}^{\max }$ & $\mathbf{T}_{\mathbf{C}}{ }^{\text {mean }}$ & $\mu_{1}^{\operatorname{mean}}$ & $\mathbf{I}_{\gamma}^{\operatorname{mean}}$ & $\mathbf{G}_{\beta}^{\text {mean }}$ \\
\hline $1.0221 \mathrm{e}+2$ & $1.6341 \mathrm{e}+5$ & $2.9203 \mathrm{e}+3$ & $1.3232 \mathrm{e}+2$ & 6.6035 & $2.0018 \mathrm{e}+4$ \\
\hline
\end{tabular}

In each cluster a patient with the smallest know tumor size is used as initial condition (given in table 3) for the dynamics computations presented in figures 4 and 5. However, any patient in the "below average" and "no data" group can be reasonable used as initial condition. The resulting dynamics is given by cluster on figures A1-A5.

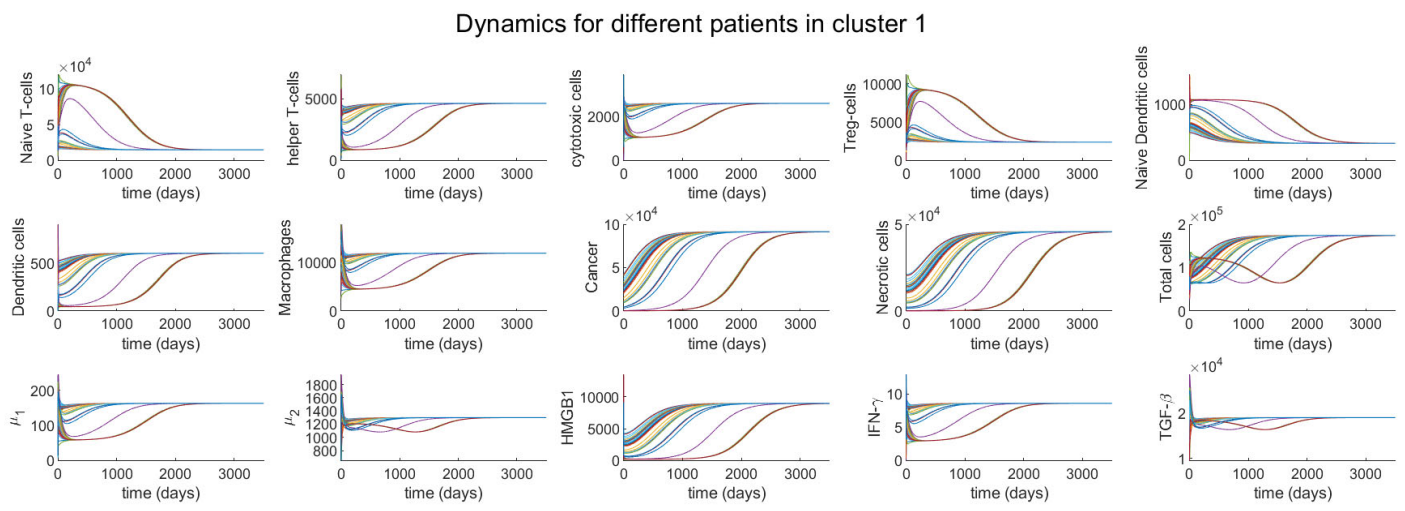

Figure A1: Different initial conditions for cluster 1. Based on patients in the "below average" and "no data" categories. 

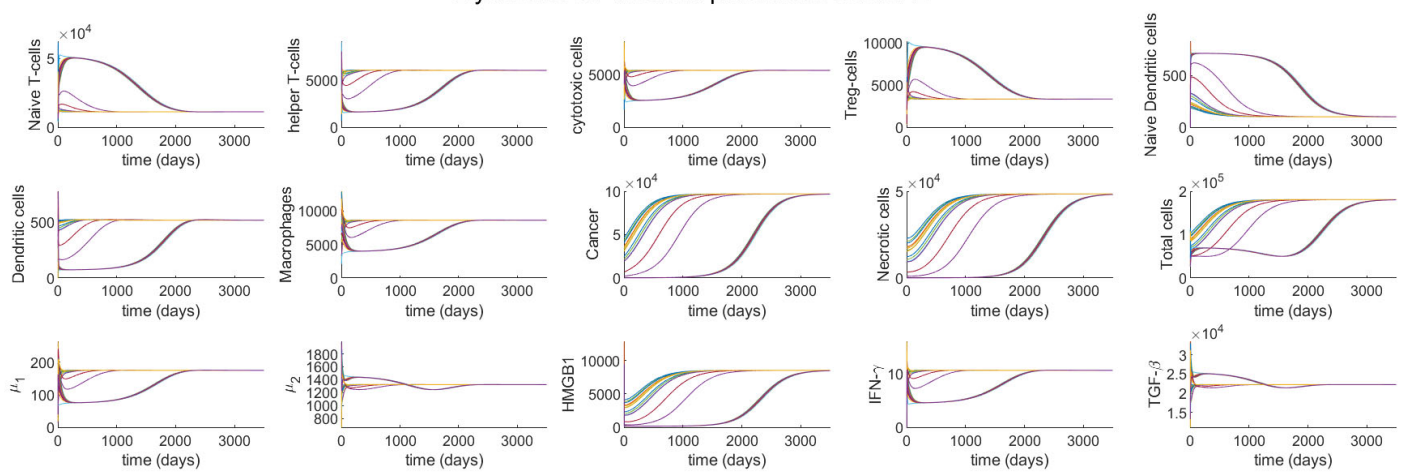

Figure A2: Different initial conditions for cluster 2. Based on patients in the "below average" and "no data" categories.

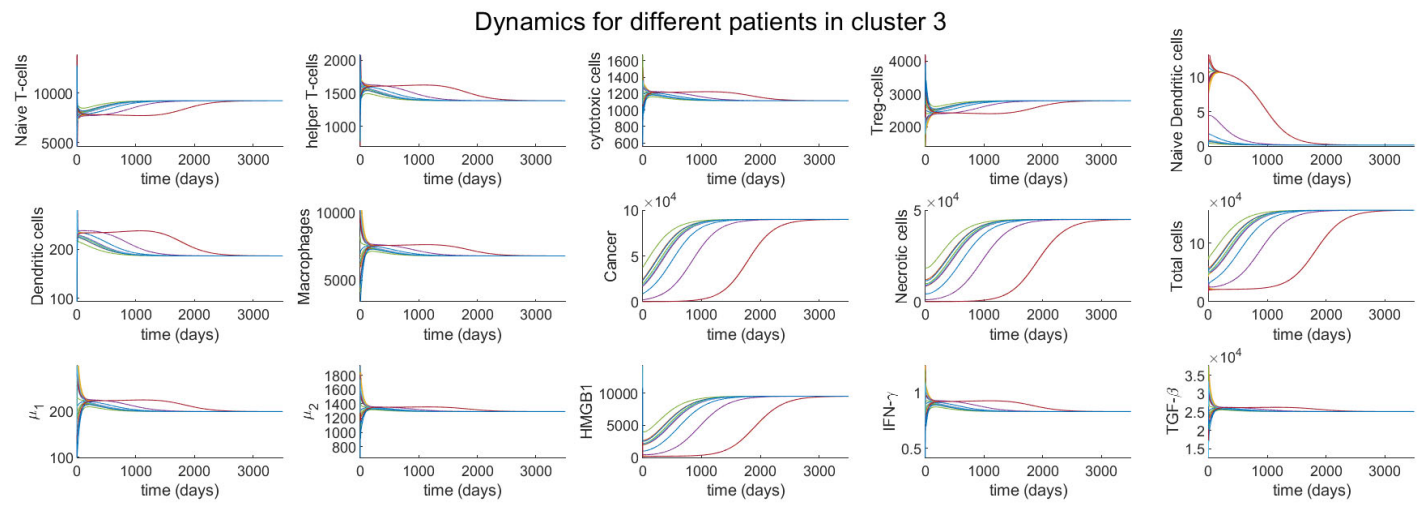

Figure A3: Different initial conditions for cluster 3. Based on patients in the "below average" and "no data" categories.

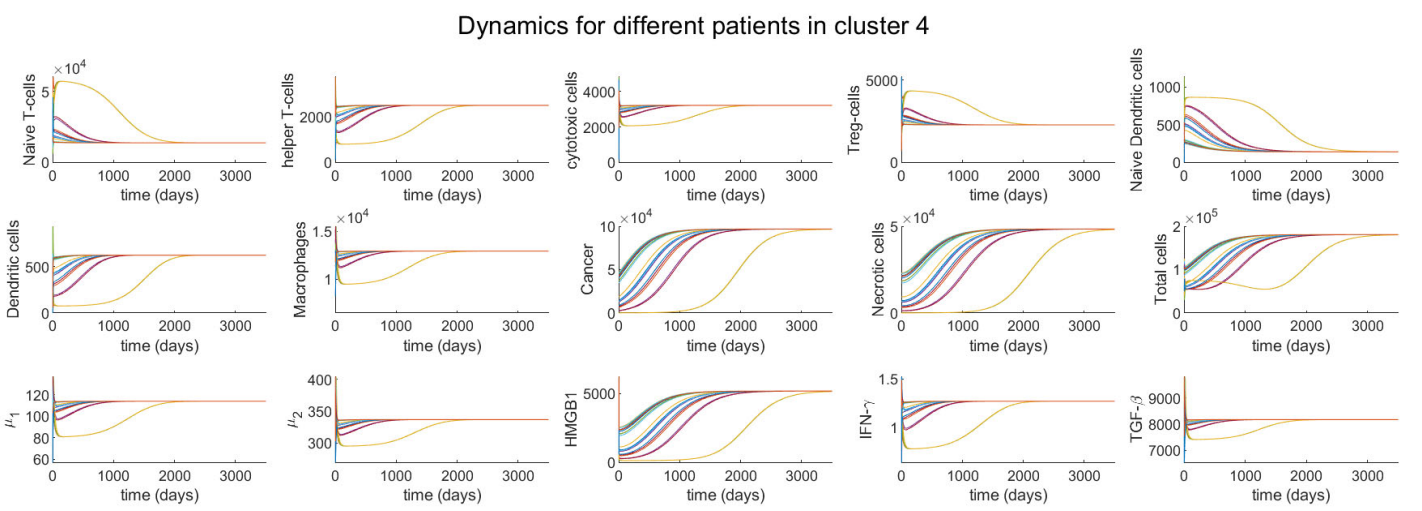

Figure A4: Different initial conditions for cluster 4. Based on patients in the "below average" and "no data" categories. 
bioRxiv preprint doi: https://doi.org/10.1101/2020.11.02.365668; this version posted November 4, 2020. The copyright holder for this preprint (which was not certified by peer review) is the author/funder, who has granted bioRxiv a license to display the preprint in perpetuity. It is made available under aCC-BY-NC 4.0 International license.

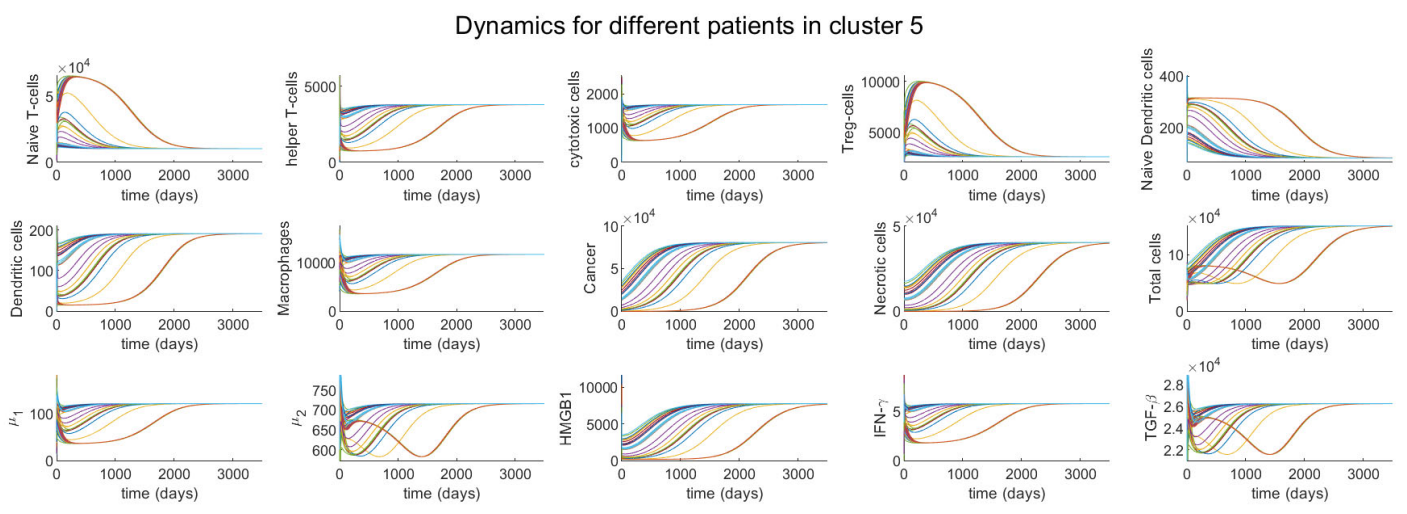

Figure A5: Different initial conditions for cluster 5. Based on patients in the "below average" and "no data" categories. 